\title{
Interleaved Switched-Capacitor Bidirectional DC-DC Converter with Wide Voltage-Gain Range for Energy Storage Systems
}

\author{
Yun Zhang, Member, IEEE, Yongping Gao, Jing Li, Member, IEEE, Mark Sumner, Senior Member, IEEE
}

\begin{abstract}
In this paper, an interleaved switched-capacitor bidirectional DC-DC converter with a high step-up/step-down voltage gain is proposed. The interleaved structure is adopted in the low-voltage side of this converter to reduce the ripple of the current through the low-voltage side, and the series-connected structure is adopted in the high-voltage side to achieve the high step-up/step-down voltage gain. In addition, the bidirectional synchronous rectification operations are carried out without requiring any extra hardware, and the efficiency of the converter is improved. Furthermore, the operating principles, voltage and current stresses, and current ripple characteristics of the converter are analyzed. Finally, a $1 \mathrm{~kW}$ prototype has been developed which verifies a wide voltage-gain range of this converter between the variable low-voltage side $(50 \mathrm{~V}-120 \mathrm{~V})$ and the constant high-voltage side $(400 \mathrm{~V})$. The maximum efficiency of the converter is $95.21 \%$ in the step-up mode and $95.30 \%$ in the step-down mode. The experimental results also validate the feasibility and the effectiveness of the proposed topology.
\end{abstract}

Index Terms-Bidirectional DC-DC converter, Interleaved, Switched-capacitor, Synchronous rectification, Wide-voltage-gain range

\section{INTRODUCTION}

With the aggravation of the global energy crisis and the deterioration of the environment pollution, the renewable energy systems become very important in the world [1], [2] . However, the renewable energy systems, including photo-voltaic systems and wind-power generating systems, cannot provide a stable power and supply enough instantaneous power when the load power suddenly increases. Energy storage systems, which are used to compensate the power fluctuation between the power generation side and the load side, play an important role in renewable energy power systems [3], [4] . A bidirectional DC-DC converter is a key device for interfacing an energy storage element such as a battery pack or a super-capacitor pack, with a DC bus [5], [6]. The voltage of a storage battery is typically $48 \mathrm{~V}$ or lower, while the voltage of a DC bus is $400 \mathrm{~V}$ or higher [7]. Thus, a bidirectional DC-DC converter with a wide voltage-gain range is desired for energy storage systems to connect a low-voltage battery with a high-voltage DC bus.

There are two different types of bidirectional DC-DC converters in different applications, which include the isolated converters and non-isolated converters. The isolated converters include the Flyback, the Forward-Flyback, the half-bridge and the full-bridge. High voltage-gain is obtained by adjusting the turns ratio of the high frequency transformer. However, the leakage inductance of the transformer results in high voltage spikes on semiconductors. In order to reduce the voltage stress caused by the leakage inductance, a full bridge bidirectional DC-DC converter with a Flyback snubber circuit [8] and a bidirectional DC-DC converter with an active clamp circuit [9] were proposed. Although the energy of the leakage inductor can be recycled, more additional circuits are required. Besides, when the input and the output voltages cannot match the turns ratio of the transformer, the switching loss will increase dramatically [10] .

The non-isolated converters include the Cuk, Sepic/Zeta, coupled-inductor, conventional buck-boost, three-level [11] -[14], multi-level and switched-capacitor [15]. Due to the cascaded configurations of two power stages, conversion efficiencies of Cuk and Sepic/Zeta are lower [16], [17] . Coupled-inductor converters can achieve a high voltage gain by adjusting the turns ratio of the coupled inductor [18], but the problem associated with the leakage inductor is still difficult to be solved and the converter's power converting and transferring capabilities are limited by the capacity of the magnetic core. By utilizing a coupled-inductor, the Sepic converter has been modified, and a high efficiency and high voltage-gain bidirectional DC-DC converter with soft-switching was proposed in [19]. But it requires extra active power semiconductors and capacitors. Conventional buck-boost converters are good candidates for low-voltage applications due to its high efficiency and low cost. Unfortunately, the drawbacks including the narrow voltage conversion range, the high voltage stress and extreme duty cycles of semiconductors make them not suitable for energy storage applications. Though the conventional two-phase interleaved bidirectional DC-DC converter in [20] can reduce low-voltage side current ripples, but this converter still has disadvantages including the narrow voltage conversion range and the high voltage stress for power semiconductors. The voltage stress of power semiconductors of the bidirectional three-level DC-DC converters in [11], [12] is half that of the conventional two-phase interleaved bidirectional DC-DC converter, but its voltage-gain range is still narrow. Besides, the low-voltage and high-voltage side grounds of this converter are connected by a power semiconductor, the potential difference between the two grounds is a high frequency PWM voltage, which may result in more maintenance issues and EMI problems. The low-voltage and high-voltage sides of the bidirectional three-level DC-DC converter in [14] share the common ground, but the voltage-gain of this converter is still limited. In addition, this converter requires the complicated control scheme to balance the flying-capacitor voltage. The converters in [13], and [21] can achieve a high voltage gain, and the low voltage stress of power semiconductors. However, these converters need more power semiconductors, and require additional hardware circuits and control strategies to maintain the balanced voltage stress of 
power semiconductors. The switched-capacitor converter structures and control strategies are simple and easy to expand. Different charging and discharging paths of the capacitors transfer energy to either the low-voltage or the high-voltage side to achieve a high voltage gain. Single capacitor bidirectional switched-capacitor converters were proposed in [22] , [23], but the converter's efficiency is low. To reduce the input current ripple, interleaved switched-capacitor converters have been proposed in [24] -[27]. However, the converter in [24] needs more components, and the inductor currents of the converter in [25] are unbalanced when $D_{\mathrm{b}}$ is not equal to $2 D_{\mathrm{a}}$. Although the bidirectional DC-DC converters in [26], and [27] just need four semiconductors, the maximum voltage stress of the converter in [26] is that of the high voltage side, and the maximum voltage stress of the converter in [27] is higher than that of the high voltage side. The bidirectional converters in [28], and [29] only require three semiconductors. But their voltage-gain ranges are still small. In addition, the low-voltage and high-voltage side grounds of these converter are connected by a power semiconductor or an inductor, which will also cause extra EMI problems. Finally, the high voltage-gain converter in [30] needs more power components and fails to achieve bidirectional power flows. In addition, the balanced inductor currents just can be achieved when the number of the voltage multiplier stages is odd. The converter in [31] suffers from the huge current ripple in the low-voltage side.

These non-isolated bidirectional DC-DC converters referred above cannot simultaneously achieve the low current ripple, the low voltage stress of power semiconductors and the wide voltage-gain range. In order to solve this problem, an interleaved switched-capacitor bidirectional DC-DC converter is proposed in this paper. Comparing with the conventional two-phase interleaved bidirectional DC-DC converter and the bidirectional three-level DC-DC converter, the proposed converter has advantages including low current ripple, low voltage-stress of power semiconductors and wide voltage-gain range. In addition, the connection between the low-voltage and the high-voltage side grounds of the proposed converter is a capacitor rather than a power semiconductor. To achieve a high step-up gain, the capacitors are charged in parallel and discharged in series in the step-up mode. Opposite to the step-up mode, the high step-down ratio can also be obtained because two capacitors are charged in series and discharged in parallel. Furthermore, the capacitor voltage of the proposed converter is half of the high-voltage side voltage, and the efficiency is improved by synchronous rectification operation. This paper is organized as follows. In Section II, the topology of the interleaved switched-capacitor bidirectional DC-DC converter is presented. In Section III, the operating principles of the proposed converter are analyzed in detail. The steady-state characteristics of the converter are analyzed in Section IV and experimental results are analyzed in Section V.

\section{The Proposed Converter}

The proposed interleaved switched-capacitor bidirectional DC-DC Converter is shown in Fig. 1. This converter is composed of four modules. $C_{\text {low }}$ is the energy storage/filter capacitor of the low-voltage side. Module 1 includes power semiconductors $Q_{1}, Q_{2}$, and energy storage/filter inductors $L_{1}$, $L_{2}$. In addition, $L_{1}-Q_{1}$ and $L_{2}-Q_{2}$ form the parallel structure of the low-voltage side. Module 2 is a switched-capacitor network, including switched-capacitor units $C_{1}-Q_{3}, C_{2}-Q_{4}$ and $C_{3}-Q_{5}$. The interleaved structure is used in the low-voltage side of this converter. In this case, the duty cycles of $Q_{1}$ and $Q_{2}$ are the same, and the phase difference between the gate signals $S_{1}$ and $\mathrm{S}_{2}$ is $180^{\circ}$. The low-voltage side, Module 1 , Module 2 and the high-voltage side form the bidirectional DC-DC converter with the structure of the low-voltage-side in parallel and the high-voltage-side in series.

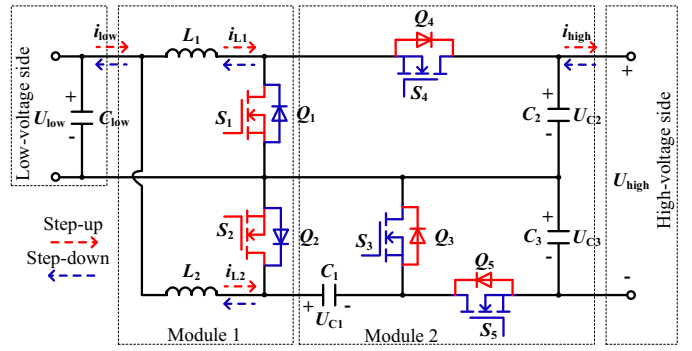

Fig. 1 The proposed topology of the interleaved switched-capacitor bidirectional DC-DC Converter.

\section{Operating Principles}

To simplify the steady-state characteristics analysis of the proposed converter, several reasonable assumptions about the operating conditions are made as follows: (a) all the power semiconductors and energy storage components of the converter are treated as ideal ones, and the converter operates in the continuous conduction mode (CCM); (b) all the capacitances are large enough that each capacitor voltage is considered as constant in each switching period.

\section{A. Step-Up Mode}

When the energy flows from the low-voltage side to the high-voltage side, the output voltage $U_{\text {high }}$ is stepped up from $U_{\text {low }}$ by controlling the power semiconductors of $Q_{1}$, and $Q_{2}$, and the anti-parallel diodes of $Q_{3}, Q_{4}$ and $Q_{5}$. The relationship between $d_{1}$ and $d_{2}$ can be written as $d_{1}=d_{2}=d_{\text {Boost }}$, where $d_{1}$ and $d_{2}$ are the duty cycles of $Q_{1}$ and $Q_{2}$ respectively. Fig. 2 shows the typical waveforms in the step-up mode, and Fig. 3 shows the current flow path of the proposed converter.

Mode I: The power semiconductor $Q_{1}$ is turned on and $Q_{2}$ is turned off. The anti-parallel diode of $Q_{3}$ is turned on, while the anti-parallel diodes of $Q_{4}$ and $Q_{5}$ are turned off. The current flow path of the proposed converter is illustrated in Fig. 3(a). The energy is transferred from the DC source $U_{\text {low }}$ to the inductor $L_{1}$. Meantime, $C_{1}$ is being charged by inductor $L_{2}$, while $C_{2}$ and $C_{3}$ are discharging. $C_{2}$ and $C_{3}$ are connected in series to provide energy for the load in the high voltage side.

Mode II: The power semiconductors $Q_{1}$ and $Q_{2}$ are turned off. The anti-parallel diodes of $Q_{3}$ and $Q_{4}$ are turned on, while the anti-parallel diode of $Q_{5}$ is turned off. The current flow path of the proposed converter is given in Fig. 3(b). Inductors $L_{1}$ and $L_{2}$ are discharging. Meantime, $C_{1}$ is charging from inductor $L_{2}$, while $C_{3}$ is discharging. The DC source $U_{\text {low }}, L_{1}$ and $C_{3}$ output energy to the load.

Mode III: The power semiconductor $Q_{1}$ is turned off and $Q_{2}$ 
is turned on. The anti-parallel diode of $Q_{3}$ is turned off, while the anti-parallel diodes of $Q_{4}$ and $Q_{5}$ are turned on. The current flow path of the proposed converter is shown in Fig. 3(c). Inductor $L_{1}$ is discharging, while $L_{2}$ is charged by the DC source. Meantime, $C_{3}$ is charged by $C_{1}$, while $C_{2}$ is charged by inductor $L_{1}$. The DC source $U_{\text {low }}, L_{1}$ and $C_{1}$ output energy to the load.

Mode IV: Power semiconductors $Q_{1}$ and $Q_{2}$ are turned on. The anti-parallel diodes of $Q_{3}$ and $Q_{4}$ are turned off, while the anti-parallel diode of $Q_{5}$ is turned on. The current flow path of the proposed converter is displayed in Fig. 3(d). Inductors $L_{1}$ and $L_{2}$ are charged by the DC source $U_{\text {low }}$ in parallel. Meantime, $C_{1}$ and $C_{2}$ are discharging in series to provide energy for the load.

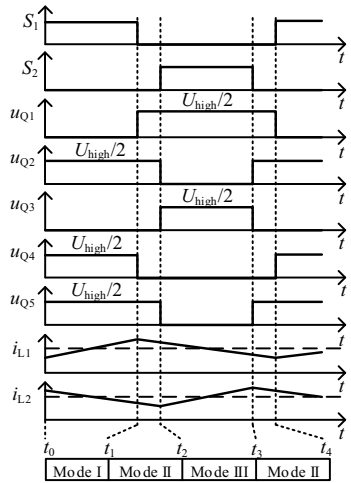

(a)

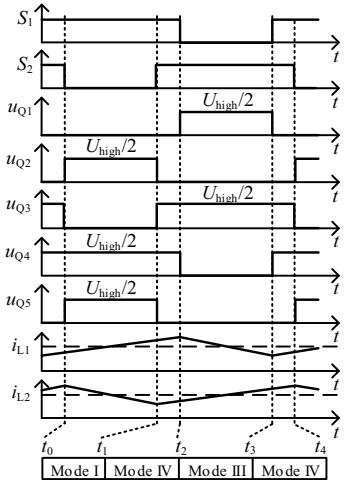

(b)
Fig. 2 Typical waveforms of the proposed converter in the step-up mode. (a) $0<d_{\text {Boost }}<0$.5. (b) $0.5 \leq d_{\text {Boost }}<1$.

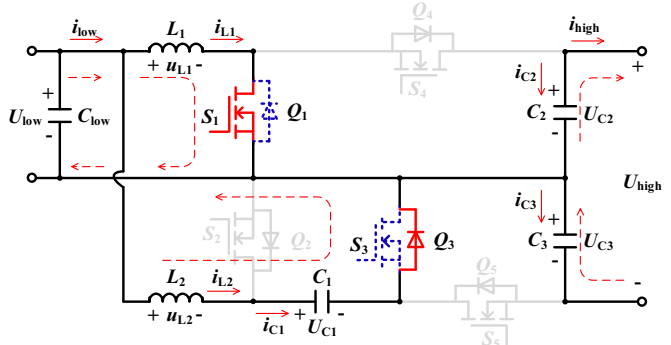

(a)

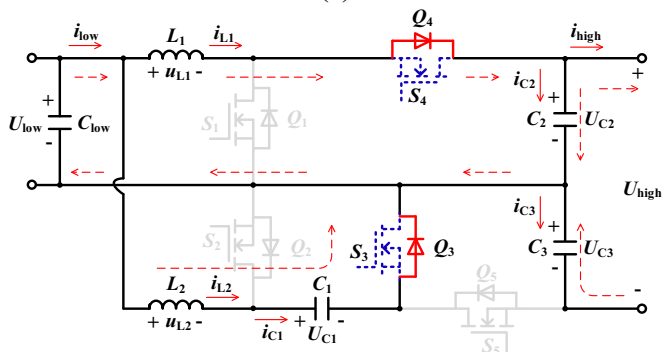

(b)

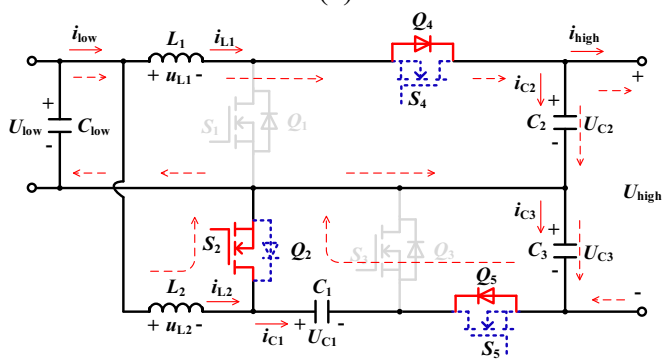

(c)

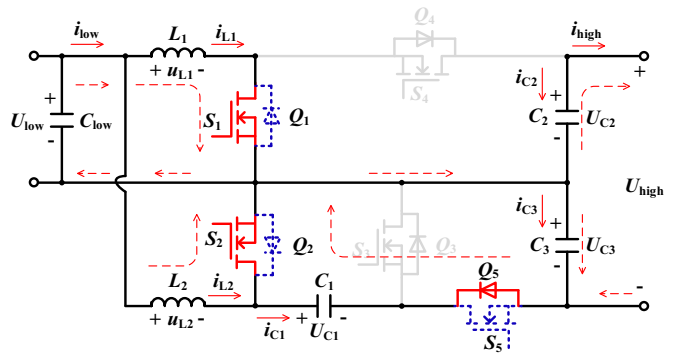

(d)

Fig. 3 Current flow path of the proposed converter in the step-up mode. (a) Mode I $S_{1} S_{2}=10$. (b) Mode II $S_{1} S_{2}=00$. (c) Mode III $S_{1} S_{2}=01$. (d) Mode IV $S_{1} S_{2}=11$.

\section{B. Step-Down Mode}

When energy flows from the high-voltage side to the low-voltage side, the output voltage $U_{\text {low }}$ is stepped down from $U_{\text {high }}$ by controlling the power semiconductors $Q_{3}, Q_{4}$ and $Q_{5}$, and the anti-parallel diodes of $Q_{1}$ and $Q_{2}$. The relationship between $d_{3}$ and $d_{4}$ can be written as $d_{3}=d_{4}=d_{\text {Buck, where }} d_{3}$ and $d_{4}$ are the duty cycles of $Q_{3}$ and $Q_{4}$ respectively. Fig. 4 shows the typical waveforms in the step-down mode, and Fig. 5 shows the current flow path of the proposed converter.

Mode I: The power semiconductor $Q_{3}$ is turned on, while $Q_{4}$ and $Q_{5}$ are turned off. The anti-parallel diode of $Q_{1}$ is turned on, and the anti-parallel diode of $Q_{2}$ is turned off. The current flow path of the proposed converter is shown in Fig. 5(a). $C_{2}$ and $C_{3}$ are charged by the DC source $U_{\text {high }}$ in series. Meantime, inductors $L_{1}, L_{2}$ and $C_{1}$ are discharging to provide energy for the load in the low voltage side.

Mode II: Power semiconductors $Q_{3}$ and $Q_{4}$ are turned on, while $Q_{5}$ is turned off. The anti-parallel diodes of $Q_{1}$ and $Q_{2}$ are turned off. The current flow path is shown in Fig. 5(b). $C_{1}$ is discharging to transfer energy to inductor $L_{2}$, and simultaneously outputting energy to the load. Meantime, the DC source $U_{\text {high }}$ charges $L_{1}$ and $C_{3}$, and simultaneously outputs energy to the load. In addition, $C_{2}$ is discharging to supply energy to $L_{1}$ and the load.

Mode III: The power semiconductor $Q_{3}$ is turned off, while $Q_{4}$ and $Q_{5}$ are turned on. The anti-parallel diode of $Q_{1}$ is turned off, and the anti-parallel diode of $Q_{2}$ is turned on. The current flow path of the proposed converter is shown in Fig. 5(c). Inductor $L_{2}$ is discharging to provide energy for the load. Meantime, the DC source $U_{\text {high }}$ charges $L_{1}$ and $C_{1}$, and simultaneously provide energy for the load. In addition, $C_{2}$ is discharging to supply energy to $L_{1}$ and the load, and $C_{3}$ is discharging to output energy to $C_{1}$.

Mode IV: Power semiconductors $Q_{3}$ and $Q_{4}$ are turned off, while $Q_{5}$ is turned on. The anti-parallel diodes of $Q_{1}$ and $Q_{2}$ are turned on. The current low path of the proposed converter is shown in Fig. 5(d). $L_{1}$ and $L_{2}$ are discharging to provide energy for the load in parallel. Meantime, the DC source $U_{\text {high }}$ charges $C_{1}$ and $C_{2}$ in series, and $C_{3}$ is discharging to supply energy to $C_{1}$. 


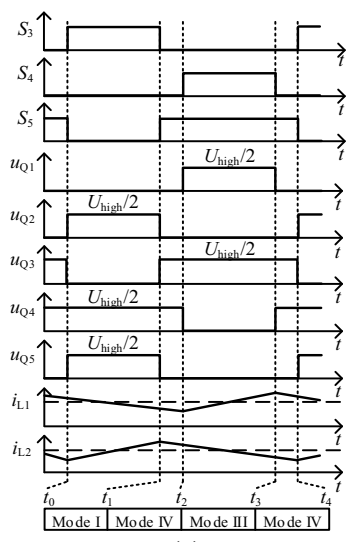

(a)

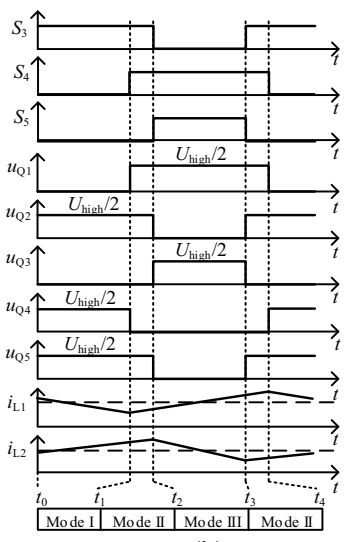

(b)
Fig. 4 Typical waveforms of the proposed converter in the step-down mode. (a) $0<d_{\text {Buck }}<0.5$. (b) $0.5 \leq d_{\text {Buck }}<1$.

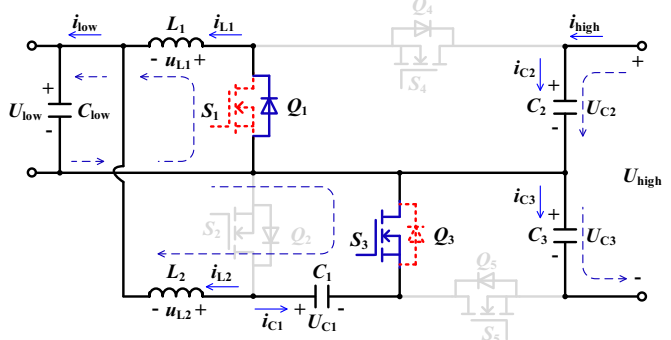

(a)

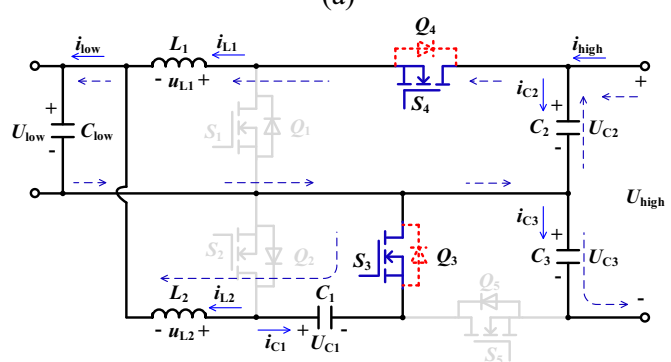

(b)

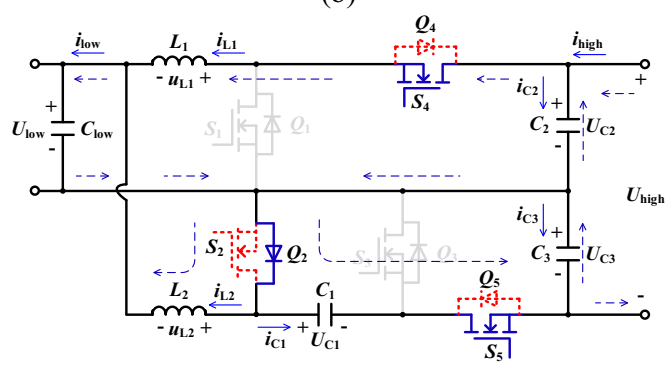

(c)

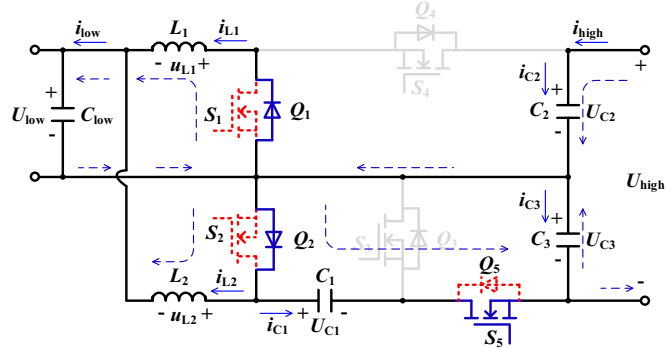

(d)

Fig. 5 Current flow path of the proposed converter in the step-down mode. (a) Mode I $S_{3} S_{4} S_{5}=100$. (b) Mode II $S_{3} S_{4} S_{5}=110$. (c) Mode III $S_{3} S_{4} S_{5}=011$. (d) Mode IV $S_{3} S_{4} S_{5}=001$.

\section{Synchronous rectification operation}

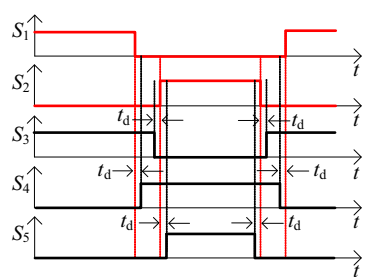

(a)

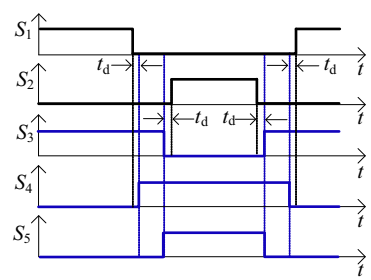

(b)

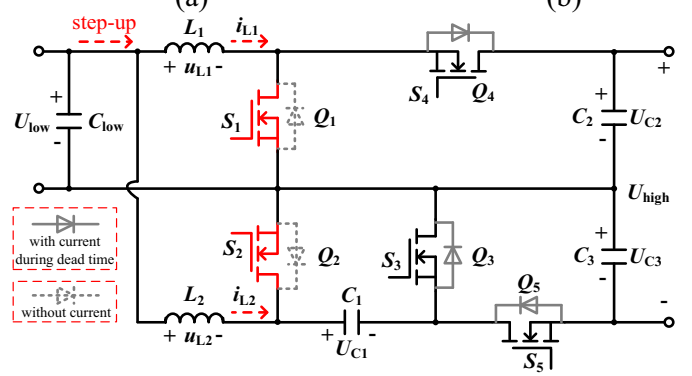

(c)

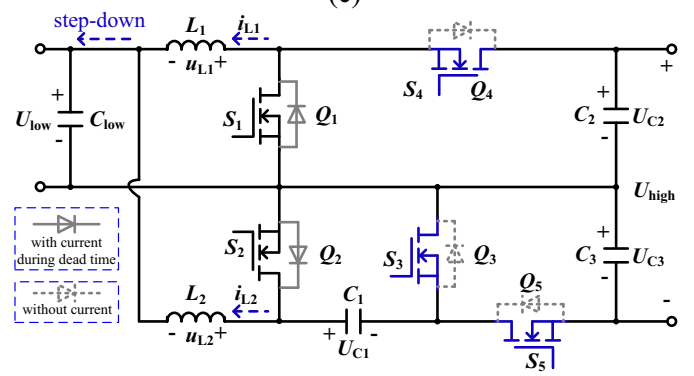

(d)

Fig. 6 Synchronous rectification operating principle of the proposed bidirectional converter. (a) Gate signals and the dead time in the step-up mode (left). (b) Gate signals and the dead time in the step-down mode (right). (c) Current flow path in the step-up mode. (d) Current flow path in the step-down mode.

As shown in Fig. 1, if the currents of the proposed interleaved switched-capacitor bidirectional converter flow into the corresponding anti-parallel diodes, it will result in the lower efficiency, as well as lower utilization of the power semiconductors. Therefore, a high step-up/step-down ratio switched-capacitor bidirectional DC-DC converter with synchronous rectification is proposed further in this paper.

The synchronous rectification operating principle of the switched-capacitor bidirectional converter is shown in Fig. 6. In the step-up mode, the main power semiconductors $Q_{1}$ and $Q_{2}$ switch according to gate signals $S_{1}$ and $S_{2}$ shown in Fig. 6(a). During the dead time $t_{\mathrm{d}}$, the current has to fully flow into the corresponding anti-parallel diodes of $Q_{3}, Q_{4}$ and $Q_{5}$. Otherwise, the current may flow into the controlled power semiconductors $Q_{3}, Q_{4}$ and $Q_{5}$ due to their lower on-resistances and on-state voltage drops, as shown in Fig. 6(c), by means of the gate signals $S_{3}, S_{4}$ and $S_{5}$ shown in Fig. 6(a). Similarly, in the step-down mode, the main power semiconductors $Q_{3}, Q_{4}$ and $Q_{5}$ switch according to gate signals $S_{3}, S_{4}$ and $S_{5}$ shown in Fig. 6(b). During the dead time $t_{\mathrm{d}}$, the current also has to fully flow into the anti-parallel diodes of $Q_{1}$ and $Q_{2}$. Otherwise, according to the gate signals $S_{1}$ and $S_{2}$ shown in Fig. 6(b), the current flows into the controlled power semiconductors $Q_{1}$ and $Q_{2}$, as shown in Fig. $6(d)$. 
Furthermore, the forward voltage drops of the anti-parallel diodes are close to zero. As a result, the controlled MOSFETs of the slave active power semiconductors can be turned on and turned off with ZVS, and the efficiency of the converter is further improved.

\section{Control strategy of bidirectional power flow}

Based on the operating principles above, the bidirectional power flow control strategy can be achieved as shown in Fig. 7. The voltages $U_{\text {high }}$ and $U_{\text {low }}$, and the current $i_{\text {low }}$ are obtained by samplings. The interleaving structure is applied to reduce the current ripples.

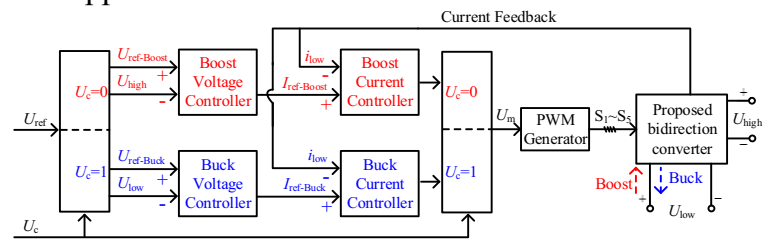

Fig. 7 Control strategy of the bidirectional power flows.

As shown in Fig. 7, the operating modes of the proposed bidirectional DC-DC converter switch between the step-down and the step-up, according to the power flow control signal $U_{\mathrm{c}}$. It operates in the step-up mode when $U_{\mathrm{c}}=0$, the voltage $U_{\text {high }}$ is controlled by the Boost voltage controller with the reference voltage $U_{\text {ref-Boost }}$ in the voltage-loop. Meantime, the feedback current $i_{\text {low }}$ is controlled by the Boost current controller with the reference current $I_{\text {ref-Boost }}$ in the current-loop. The corresponding PWM schemes as shown in Fig. 2 and Fig. 6(a) are selected to generate the gate signals $S_{1} \sim S_{5}$ in the step-up mode.

Similarly, the converter operates in the step-down mode when $U_{\mathrm{c}}=1$, the voltage $U_{\text {low }}$ is controlled by the Buck voltage controller with the reference voltage $U_{\text {ref-Buck, }}$ and the feedback current $i_{\text {low }}$ is controlled by the Buck current controller with the reference current $I_{\text {ref-Buck, }}$ which is in the opposite direction to the reference current $I_{\text {ref-Boost. The corresponding PWM schemes }}$ as shown in Fig. 4 and Fig. 6(b) are also selected to generate the gate signals $S_{1} \sim S_{5}$ in the step-down mode.

\section{Analysis Of Steady-STATe Characteristics}

\section{A. Voltage-gain in steady-state}

\section{(1) Voltage-gain in step-up mode}

As shown in Fig. 2(a) and Fig. 3(c), in the range of $0<d_{\text {Boost }}<0.5, C_{1}$ and $C_{3}$ are connected in parallel, so that the voltages of $C_{1}$ and $C_{3}$ are equal. According to Fig. 3(a)-(c) and the voltage-second balance principle on $L_{1}$ and $L_{2}$, the following equations can be obtained as

$$
\left\{\begin{array}{l}
d_{\text {Boost }} \times U_{\text {low }}=\left(1-d_{\text {Boost }}\right) \times\left(U_{\mathrm{C} 2}-U_{\text {low }}\right) \\
d_{\text {Boost }} \times U_{\text {low }}=\left(1-d_{\text {Boost }}\right) \times\left(U_{\mathrm{C} 1}-U_{\text {low }}\right) \\
U_{\mathrm{C} 1}=U_{\mathrm{C} 3}
\end{array}\right.
$$

Therefore, by simplifying (1), the following equations can be written as

$$
\left\{\begin{array}{l}
U_{\mathrm{C} 1}=U_{\mathrm{C} 2}=U_{\mathrm{C} 3}=\frac{1}{1-d_{\text {Boost }}} U_{\text {low }} \\
U_{\text {high }}=\frac{2}{1-d_{\text {Boost }}} U_{\text {low }}
\end{array}\right.
$$

According to (2), the voltage-gain of the proposed converter in the step-up mode is $2 /\left(1-d_{\text {Boost }}\right)$, which is twice as big as the voltage-gain of the conventional interleaved bidirectional DC-DC converter. In addition, the voltage stress of $C_{1}, C_{2}$ and $C_{3}$ can be reduced to half of the voltage $U_{\text {high }}$, and $U_{\mathrm{C} 2}, U_{\mathrm{C} 3}$ are self-balanced due to the switched-capacitor technique. Similarly, the corresponding voltage equations of the proposed converter within the range of $0.5 \leq d_{\text {Boost }}<1$ can also be obtained, which are the same as those within the range of $0<d_{\text {Boost }}<0.5$.

\section{(2) Voltage-gain in the step-down mode}

As shown in Fig. 4(a) and Fig. 5(c), within the range of $0.5 \leq d_{\text {Buck }}<1, C_{1}$ and $C_{3}$ are connected in parallel, so that the voltages of $C_{1}$ and $C_{3}$ are still equal. According to Fig. 5(a)-(c) and the voltage-second balance principle on $L_{1}$ and $L_{2}$, the following equations can be obtained as

$$
\left\{\begin{array}{l}
d_{\text {Buck }} \times\left(U_{\mathrm{C} 2}-U_{\text {low }}\right)=\left(1-d_{\text {Buck }}\right) \times U_{\text {low }} \\
d_{\text {Buck }} \times\left(U_{\mathrm{C} 1}-U_{\text {low }}\right)=\left(1-d_{\text {Buck }}\right) \times U_{\text {low }} \\
U_{\mathrm{C} 1}=U_{\mathrm{C} 3}
\end{array}\right.
$$

Therefore, by simplifying (3), the following equations can be written as

$$
\left\{\begin{array}{l}
U_{\mathrm{C} 1}=U_{\mathrm{C} 2}=U_{\mathrm{C} 3}=\frac{1}{2} U_{\text {high }} \\
U_{\text {low }}=\frac{d_{\text {Buck }}}{2} U_{\text {high }}
\end{array}\right.
$$

According to (4), the voltage-gain of the proposed converter in the step-down mode is $d_{\text {Buck }} / 2$, which is half of the voltage-gain of the conventional interleaved bidirectional DC-DC converter. In addition, the voltage stress of $C_{1}, C_{2}$ and $C_{3}$ are still half of the voltage $U_{\text {high, }}$ and $U_{\mathrm{C} 2}, U_{\mathrm{C} 3}$ are still self-balanced, which are the same as those in the step-up mode. Similarly, the voltage equations of the proposed converter within the range of $0.5 \leq d_{\text {Buck }}<1$ can also be obtained, which are the same as those within the range of $0<d_{\text {Buck }}<0.5$.

\section{B. Inductor currents self-balance}

\section{(1) Inductor currents self-balance in the step-up mode}

According to Fig. 3(a)-(c), the currents of $C_{1}, C_{2}$ and $C_{3}$ are as follows, within the duty cycle range $0<d_{\text {Boost }}<0.5$ in the step-up mode.

$$
\left\{\begin{array}{l}
i_{\mathrm{C} 1}= \begin{cases}I_{\mathrm{C} 1}^{\prime} & 0 \leq t<d_{\text {Boost }} T_{\mathrm{s}} \\
I_{\mathrm{L} 2} & d_{\text {Boost }} T_{\mathrm{s}} \leq t<T_{\mathrm{s}}\end{cases} \\
i_{\mathrm{C} 2}= \begin{cases}-I_{\text {high }} & 0 \leq t<d_{\text {Boost }} T_{\mathrm{s}} \\
I_{\mathrm{L} 1}-I_{\text {high }} & d_{\text {Boost }} T_{\mathrm{s}} \leq t<T_{\mathrm{s}}\end{cases} \\
i_{\mathrm{C} 3}= \begin{cases}-I_{\text {high }}-I_{\mathrm{C} 1}^{\prime} & 0 \leq t<d_{\text {Boost }} T_{\mathrm{s}} \\
-I_{\text {high }} & d_{\text {Boost }} T_{\mathrm{s}} \leq t<T_{\mathrm{s}}\end{cases}
\end{array}\right.
$$

where $I_{\mathrm{L} 1}, I_{\mathrm{L} 2}$ and $I_{\text {high }}$ are the average currents of $i_{\mathrm{L} 1}, i_{\mathrm{L} 2}$ and $i_{\text {high }}$, and $I_{\mathrm{C} 1}, I_{\mathrm{C} 2}$ and $I_{\mathrm{C} 3}$ are the average currents of $i_{\mathrm{C} 1}, i_{\mathrm{C} 2}$ and $i_{\mathrm{C} 3}$ in the step-up mode respectively. In addition, $I_{\mathrm{C} 1}^{\prime}$ is the average current of $C_{1}$ when $Q_{2}$ turns on. By applying the amp-second balance principle on capacitors $C_{1}, C_{2}$ and $C_{3}$, the following equations (6)-(8) can be obtained as 


$$
\begin{gathered}
\left\langle i_{\mathrm{C} 1}\right\rangle=0=\frac{d_{\text {Boost }} T_{\mathrm{s}} I_{\mathrm{C} 1}^{\prime}+\left(1-d_{\text {Boost }}\right) T_{\mathrm{s}} I_{\mathrm{L} 2}}{T_{\mathrm{s}}} \\
\Rightarrow I_{\mathrm{L} 2}=-\frac{d_{\text {Boost }}}{1-d_{\text {Boost }}} I_{\mathrm{C} 1}^{\prime} \\
\left\langle i_{\mathrm{C} 2}\right\rangle=0=\frac{-d_{\text {Boost }} T_{\mathrm{s}} I_{\text {high }}+\left(1-d_{\text {Boost }}\right)\left(I_{\mathrm{L} 1}-I_{\text {high }}\right)}{T_{\mathrm{s}}} \\
\Rightarrow I_{\mathrm{L} 1}=\frac{1}{1-d_{\text {Boost }}} I_{\text {high }} \\
\left\langle i_{\mathrm{C} 3}\right\rangle=0=\frac{d_{\text {Boost }} T_{\mathrm{s}}\left(-I_{\text {high }}-I_{\mathrm{C} 1}^{\prime}\right)-\left(1-d_{\text {Boost }}\right) T_{\mathrm{s}} I_{\text {high }}}{T_{\mathrm{s}}} \\
\Rightarrow I_{\mathrm{C} 1}^{\prime}=-\frac{1}{d_{\text {Boost }}} I_{\text {high }}
\end{gathered}
$$

In addition, the relationship $I_{\text {low }}=I_{\mathrm{L} 1}+I_{\mathrm{L} 2}$ can be drawn in the step-up mode, according to Fig. 3. Then, substituting (8) into (6), $I_{\text {low }}, I_{\mathrm{L} 1}$ and $I_{\mathrm{L} 2}$ can obtained as

$$
\left\{\begin{array}{l}
I_{\text {low }}=\frac{2}{1-d_{\text {Boost }}} I_{\text {high }} \\
I_{\mathrm{L} 1}=I_{\mathrm{L} 2}=\frac{1}{1-d_{\text {Boost }}} I_{\text {high }}
\end{array}\right.
$$

In terms of (9), $I_{\mathrm{L} 1}$ and $I_{\mathrm{L} 2}$ are both half of the input current $I_{\text {low }}$, i.e. the current self-balance is achieved in the step-up mode. Similarly, the corresponding current equations of the proposed converter within the duty cycle range $0.5 \leq d_{\text {Boost }}<1$ can also be obtained, which are the same as those within the duty cycle range $0<d_{\text {Boost }}<0.5$.

\section{(2) Inductor currents self-balance in the step-down mode}

The currents of $C_{1}, C_{2}$ and $C_{3}$ can be written as follows within the duty cycle range $0<d_{\text {Buck }}<0.5$, by means of Fig. 5(a), (c) and (d), in the step-down mode.

$$
\left\{\begin{array}{l}
i_{\mathrm{C} 1}= \begin{cases}-I_{\mathrm{L} 2} & 0 \leq t<d_{\mathrm{Buck}} T_{\mathrm{s}} \\
I_{\mathrm{C} 1}^{\prime} & d_{\text {Buck }} T_{\mathrm{s}} \leq t<T_{\mathrm{s}}\end{cases} \\
i_{\mathrm{C} 2}= \begin{cases}I_{\text {high }}-I_{\mathrm{L} 1} & 0 \leq t<d_{\text {Buck }} T_{\mathrm{s}} \\
I_{\text {high }} & d_{\text {Buck }} T_{\mathrm{s}} \leq t<T_{\mathrm{s}}\end{cases} \\
i_{\mathrm{C} 3}= \begin{cases}I_{\text {high }} & 0 \leq t<d_{\text {Buck }} T_{\mathrm{s}} \\
I_{\text {high }}-I_{\mathrm{C} 1}^{\prime} & d_{\text {Buck }} T_{\mathrm{s}} \leq t<T_{\mathrm{s}}\end{cases}
\end{array}\right.
$$

where $I_{\mathrm{L} 1}, I_{\mathrm{L} 2}$ and $I_{\text {high }}$ are the average currents of $i_{\mathrm{L} 1}, i_{\mathrm{L} 2}$ and $i_{\text {high }}$, and $I_{\mathrm{C} 1}, I_{\mathrm{C} 2}$ and $I_{\mathrm{C} 3}$ are the average currents of $i_{\mathrm{C} 1}, i_{\mathrm{C} 2}$ and $i_{\mathrm{C} 3}$ in the step-down mode respectively. In addition, $I_{\mathrm{C} 1}^{\prime}$ is the average current of $C_{1}$ when $Q_{3}$ is turned off. By applying the amp-second balance principle on capacitors $C_{1}, C_{2}$ and $C_{3}$, the following equations (11)-(13) can be obtained as

$$
\begin{aligned}
\left\langle i_{\mathrm{C} 1}\right\rangle & =0=\frac{-d_{\text {Buck }} T_{\mathrm{s}} I_{\mathrm{L} 2}+\left(1-d_{\text {Buck }}\right) T_{\mathrm{s}} I_{\mathrm{C} 1}^{\prime}}{T_{\mathrm{s}}} \\
& \Rightarrow I_{\mathrm{L} 2}=\frac{1-d_{\text {Buck }}}{d_{\text {Buck }}} I_{\mathrm{C} 1}^{\prime}
\end{aligned}
$$

$$
\begin{aligned}
\left\langle i_{\mathrm{C} 2}\right\rangle & =0=\frac{d_{\text {Buck }} T_{\mathrm{s}}\left(I_{\text {high }}-I_{\mathrm{L} 1}\right)+\left(1-d_{\text {Buck }}\right) I_{\text {high }}}{T_{\mathrm{s}}} \\
& \Rightarrow I_{\mathrm{L} 1}=\frac{1}{d_{\text {Buck }}} I_{\text {high }} \\
\left\langle i_{\mathrm{C} 3}\right\rangle= & =\frac{d_{\text {Buck }} T_{\mathrm{s}} I_{\text {high }}+\left(1-d_{\text {Buck }}\right) T_{\mathrm{s}}\left(I_{\text {high }}-I_{\mathrm{C} 1}^{\prime}\right)}{T_{\mathrm{s}}} \\
& \Rightarrow I_{\mathrm{C} 1}^{\prime}=\frac{1}{1-d_{\text {Buck }}} I_{\text {high }}
\end{aligned}
$$

According to Fig. 5, the current relationship $I_{\mathrm{low}}=I_{\mathrm{L} 1}+I_{\mathrm{L} 2}$ can also be drawn in the step-down mode. Then, substituting (13) into (11), $I_{\text {high, }} I_{\mathrm{L} 1}$ and $I_{\mathrm{L} 2}$ can achieved as

$$
\left\{\begin{array}{l}
I_{\text {high }}=\frac{d_{\text {Buck }}}{2} I_{\text {low }} \\
I_{\mathrm{L} 1}=I_{\mathrm{L} 2}=\frac{1}{2} I_{\text {low }}
\end{array}\right.
$$

By means of (14), $I_{\mathrm{L} 1}$ and $I_{\mathrm{L} 2}$ are also half of the input current $I_{\text {low }}$, i.e. the current self-balance is also obtained in the step-down mode. In a similar way, the corresponding current equations of the proposed converter within the duty cycle range $0.5 \leq d_{\text {Buck }}<1$ can also be obtained, which are the same as those within the duty cycle range $0<d_{\text {Buck }}<0.5$.

Based on the analysis previously described, inductor currents self-balance can be achieved within the full duty cycle range for the proposed converter, in both step-up and step-down modes. This contributes to accurate current sensing, and eliminates an extra control loop that may require high performance circuits to balance phase currents.

\section{Voltage and current stresses of power semiconductors}

\section{(1) Voltage stress}

As shown in Fig. 3(b, c) in the step-up mode and Fig. 5(b, c) in the step-down mode, power semiconductor $Q_{1}$ is turned off and $Q_{4}$ is turned on, so that $Q_{1}$ and $C_{2}$ are connected in parallel. Therefore the voltages of $Q_{1}$ and $C_{2}$ are equal. Similarly, the voltages of the other power semiconductors can also be obtained. According to (2) in the step-up mode and (4) in the step-down mode, the voltage stress for the power semiconductors can be written as follows

$$
\left\{\begin{array}{l}
U_{\mathrm{Q} 1}=U_{\mathrm{Q} 4}=U_{\mathrm{C} 2}=\frac{U_{\text {high }}}{2} \\
U_{\mathrm{Q} 2}=U_{\mathrm{Q} 3}=U_{\mathrm{C} 1}=\frac{U_{\text {high }}}{2} \\
U_{\mathrm{Q} 5}=U_{\mathrm{C} 3}=\frac{U_{\text {high }}}{2}
\end{array}\right.
$$

Based on (15), all the voltage stresses of the power semiconductors and capacitors are half of the voltage $U_{\text {high }}$.

\section{(2) Current stress}

According to Fig. 3 and (9), the current stress of the power semiconductors in the step-up mode can be obtained by applying voltage-balance principle on $C_{1}, C_{2}$ and $C_{3}$ 


$$
\left\{\begin{array}{l}
I_{\mathrm{Q} 1}=\frac{1}{1-d_{\text {Boost }}} I_{\text {high }} \\
I_{\mathrm{Q} 2}=\left(\frac{1}{1-d_{\text {Boost }}}+\frac{1}{d_{\text {Boost }}}\right) I_{\text {high }} \\
I_{\mathrm{Q} 3}=I_{\mathrm{Q} 4}=\frac{1}{1-d_{\text {Boost }}} I_{\text {high }} \\
I_{\mathrm{Q} 5}=\frac{1}{d_{\text {Boost }}} I_{\text {high }}
\end{array}\right.
$$

Similarly, according to Fig. 5 and (14), the current stress of the power semiconductors in the step-down mode can be obtained as (17)

$$
\left\{\begin{array}{l}
I_{\mathrm{Q} 1}=\frac{1}{2} I_{\text {low }} \\
I_{\mathrm{Q} 2}=\frac{1}{2\left(1-d_{\text {Buck }}\right)} I_{\mathrm{low}} \\
I_{\mathrm{Q} 3}=I_{\mathrm{Q} 4}=\frac{1}{2} I_{\text {low }} \\
I_{\mathrm{Q} 5}=\frac{d_{\text {Buck }}}{2\left(1-d_{\text {Buck }}\right)} I_{\text {low }}
\end{array}\right.
$$

Based on (16) and (17), it can be seen that the current stress of $Q_{2}$ is higher than that of $Q_{1}$. But it is easier to choose a MOSFET with the high rated current rather than the one with the high rated voltage. Furthermore, the proposed bidirectional converter can obtain a high voltage gain while the duty cycle is in the range of $0.5<d_{\text {Boost }}<1$ in the step-up mode or $0<d_{\text {Buck }}<0.5$ in the step-down mode. Therefore, the difference of the current stress between $Q_{1}$ and $Q_{2}$ is limited, and it will not affect the selection of the power semiconductors.

\section{Analysis of current ripples}

\section{(1) Analysis of current ripples in the step-up mode}

In the step-up mode within the range of $0<d_{\text {Boost }}<0.5$, it is assumed that $L_{1}=L_{2}=L$. According to Fig. 3, the current ripples of $i_{\mathrm{L} 1}, i_{\mathrm{L} 2}$ and $i_{\text {low }}$ can be derived as follows

$$
\left\{\begin{array}{l}
\Delta i_{\mathrm{L} 1}=\Delta i_{\mathrm{L} 2}=\frac{d_{\text {Boost }} \times\left(1-d_{\text {Boost }}\right) \times T_{\mathrm{s}} \times U_{\text {high }}}{2 L} \\
\Delta i_{\text {low }}=\frac{d_{\text {Boost }} \times\left(1-2 d_{\text {Boost }}\right) \times T_{\mathrm{s}} \times U_{\text {high }}}{2 L}
\end{array}\right.
$$

Where $\Delta i_{\mathrm{L} 1}, \Delta i_{\mathrm{L} 2}$ and $\Delta i_{\text {low }}$ are the current ripples of $i_{\mathrm{L} 1}, i_{\mathrm{L} 2}$ and $i_{\text {low. }}$ Similarly, the current ripples of $i_{\mathrm{L} 1}, i_{\mathrm{L} 2}$ and $i_{\text {low }}$ within the range of $0.5 \leq d_{\text {Boost }}<1$ can be described as follows

$$
\left\{\begin{array}{l}
\Delta i_{\mathrm{L} 1}=\Delta i_{\mathrm{L} 2}=\frac{d_{\text {Boost }} \times\left(1-d_{\text {Boost }}\right) \times T_{\mathrm{s}} \times U_{\text {high }}}{2 L} \\
\Delta i_{\text {low }}=\frac{\left(2 d_{\text {Boost }}-1\right) \times\left(1-d_{\text {Boost }}\right) \times T_{\mathrm{s}} \times U_{\text {high }}}{2 L}
\end{array}\right.
$$

\section{(2) Analysis of current ripples in the step-down mode}

In the step-down mode within the range of $0<d_{\text {Buck }}<0.5$, it is also assumed that $L_{1}=L_{2}=L$. According to Fig. 5, the current ripples of $i_{\mathrm{L} 1}, i_{\mathrm{L} 2}$ and $i_{\text {low }}$ can be derived as follows

$$
\left\{\begin{array}{l}
\Delta i_{\mathrm{L} 1}=\Delta i_{\mathrm{L} 2}=\frac{d_{\text {Buck }} \times\left(1-d_{\text {Buck }}\right) \times T_{\mathrm{s}} \times U_{\text {high }}}{2 L} \\
\Delta i_{\text {low }}=\frac{d_{\text {Buck }} \times\left(1-2 d_{\text {Buck }}\right) \times T_{\mathrm{s}} \times U_{\text {high }}}{2 L}
\end{array}\right.
$$

Where $\Delta i_{\mathrm{L} 1}, \Delta i_{\mathrm{L} 2}$ and $\Delta i_{\text {low }}$ are the current ripples of $i_{\mathrm{L} 1}, i_{\mathrm{L} 2}$ and $i_{\text {low. }}$ Similarly, the current ripples of $i_{\mathrm{L} 1}, i_{\mathrm{L} 2}$ and $i_{\text {low }}$ within the range of $0.5 \leq d_{\text {Buck }}<1$ can be described as follows

$$
\left\{\begin{array}{l}
\Delta i_{\mathrm{L} 1}=\Delta i_{\mathrm{L} 2}=\frac{d_{\text {Buck }} \times\left(1-d_{\text {Buck }}\right) \times T_{\mathrm{s}} \times U_{\text {high }}}{2 L} \\
\Delta i_{\text {low }}=\frac{\left(2 d_{\text {Buck }}-1\right) \times\left(1-d_{\text {Buck }}\right) \times T_{\mathrm{s}} \times U_{\text {high }}}{2 L}
\end{array}\right.
$$

Assuming that $L_{1}=L_{2}=L=350 \mu \mathrm{H}, f_{\mathrm{s}}=20 \mathrm{kHz}, U_{\mathrm{high}}=400 \mathrm{~V}$, $U_{\text {low }}=50 \mathrm{~V} \sim 120 \mathrm{~V}$, and the rated output power $P_{\mathrm{n}}=1 \mathrm{~kW}$. The current ripple rate of $i_{\mathrm{L} 1}, i_{\mathrm{L} 2}$ and $i_{\text {low }}$ is shown in Fig. 8, where $\Delta i / I$ is defined as the current ripple rate. According to Fig. 8 , the current ripple of the low-voltage side current $i_{\text {low }}$ is smaller than those of $i_{\mathrm{L} 1}$ and $i_{\mathrm{L} 2}$ in both step-up and step-down modes. When $U_{\text {high }}=400 \mathrm{~V}$ and $U_{\text {low }}=50 \mathrm{~V} \sim 120 \mathrm{~V}$, the duty cycle varies in the range of $0.4<d_{\text {Boost }}<0.75$ in the step-up mode according to (2), and varies in the range of $0.25<d_{\text {Buck }}<0.6$ in the step-down mode in terms of (4). The current ripple rate of the low-voltage side current $i_{\text {low }}$ is further reduced within the corresponding duty cycle range. Taking the step-up operating state as an example, when DC source is in the range of $U_{\text {low }}=50 \mathrm{~V} \sim 120 \mathrm{~V}$, the minimum ripple rate of the low-voltage side current is $0 \%$ when the duty cycle is $d_{\text {Boost }}=0.5$. In the range of $0.4 \leq d_{\text {Boost }}<0.5$, the maximum ripple rate of the low-voltage side current arrives at $27.4 \%$ when the duty cycle is $d_{\text {Boost }}=0.4$. In addition, the maximum current ripple rate of the low-voltage side arrives at $21.1 \%$ when the duty cycle is $d_{\text {Boost }}=0.67$ within the range of $0.5<d_{\text {Boost }}<0.75$.

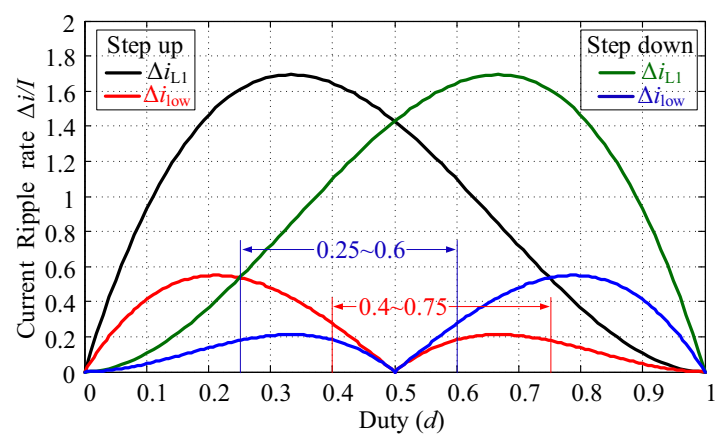

Fig. 8 The current ripple rate of $i_{\mathrm{L} 1}, i_{\mathrm{L} 2}$ and $i_{\text {low. }}$

\section{E. Comparisons with other bidirectional solutions}

According to the analysis above, the comparisons can be drawn among the proposed and the other bidirectional solutions in the step-up mode, as shown in Tab. 1. The bidirectional DC-DC converter in [14] only needs one inductor, but its ideal voltage-gain $1 /(1-\mathrm{d})$ is limited due to the effects of parasitic resistance and extreme duty cycles. Although the voltage stress across the four semiconductors of this converter is half of the high-side voltage $U_{\text {high, }}$ the current stress of the power semiconductors is rather high. In addition, this converter requires a complicate control scheme to balance the flying-capacitor voltage. The interleaved bidirectional DC-DC 
Tab. 1 Comparisons among the proposed and the other bidirectional solutions

\begin{tabular}{|c|c|c|c|c|c|}
\hline $\begin{array}{l}\text { Bidirectional } \\
\text { Solutions }\end{array}$ & Voltage Gain & $\begin{array}{c}\text { Amount of } \\
\text { Semiconductors }\end{array}$ & $\begin{array}{l}\text { Amount of } \\
\text { Inductors }\end{array}$ & $\begin{array}{c}\text { Maximum Voltage } \\
\text { Stress of } \\
\text { Semiconductors }\end{array}$ & $\begin{array}{c}\text { Inductor Currents } \\
\text { Balancing }\end{array}$ \\
\hline Converter in [14] & $U_{\text {low }} /(1-d)$ & 4 & 1 & $U_{\text {high }} / 2$ & - \\
\hline Converter in [20] & $U_{\text {low }} /(1-d)$ & 4 & 2 & $U_{\text {high }}$ & YES \\
\hline Converter in [25] & $3 U_{\text {low }} /(1-d)$ & 5 & 2 & $2 U_{\text {high }} / 3$ & When $D_{\mathrm{b}}=2 D_{\mathrm{a}}$ \\
\hline Converter in [26] & $2 U_{\text {low }} /(1-d)$ & 4 & 2 & $U_{\text {high }}$ & YES \\
\hline Converter in [27] & $U_{\text {low }} /(1-d)^{2}$ & 4 & 2 & $U_{\text {high }}+U_{\text {high }}(1-d)$ & When $d=0.5$ \\
\hline Proposed converter & $2 U_{\text {low }} /(1-d)$ & 5 & 2 & $U_{\text {high }} / 2$ & YES \\
\hline
\end{tabular}

converter in [20] can reduce the current ripples in the low-voltage side, but it still has the disadvantages including the small voltage gain range and the high voltage stress across the power semiconductors. The interleaved bidirectional DC-DC converters in [25] -[27] have achieved a high voltage-gain, but the maximum voltage stress across the semiconductors of these converters are $2 U_{\text {high }} / 3, U_{\text {high }}$ and $U_{\text {high }}+U_{\text {high }}(1-d)$ respectively, rather than $U_{\text {high }} / 2$, which will increase the switching losses and reduce the conversion efficiency. Besides, the converter in [27] can only achieve the inductor currents balance when the duty cycles are $d=0.5$, and the inductor currents of the converter in [25] are unbalanced when $D_{\mathrm{b}}$ is not equal to $2 D_{\mathrm{a}}$. Regarding the proposed interleaved bidirectional DC-DC converter, the number of main components is equal to that of the converter in [25], the voltage stress across all semiconductors and capacitors is $U_{\text {high }} / 2$, and its voltage gain is higher than that in [14] and [20] . In addition, the inductor currents and the capacitor voltage self-balances can also be obtained within the full duty cycle range, in both step-up and step-down modes.

\section{A. Small-signal modeling}

It is assumed that the power semiconductors, the inductors, and the capacitors are all ideal. Then, the average model and the small-signal model can be obtained by using the state-space averaging method. According to Fig. 3(c)-(d) in the step-up mode (or Fig. 5(c)-(d) in the step-down mode), $C_{1}$ and $C_{3}$ are connected in parallel when $Q_{2}$ and $Q_{5}$ turn on, and $Q_{3}$ turns off. It means the voltages across $C_{1}$ and $C_{3}$ are equal. So, there is an invalid state variable. By considering the equivalent series resistance (e.g. $r=0.23 \Omega$ for $C_{1}$ ), the coupling between the capacitors can be removed to avoid the invalid state variables.

\section{(1) Small-signal modeling in the step-up mode}

When the proposed bidirectional converter operates in the step-up mode in the range $0<d_{\text {Boost }}<0.5$, the main power semiconductors $Q_{1}$ and $Q_{2}$ have three effective switching states: $S_{1} S_{2}=[10,00,01] . u_{\text {low }}(t), u_{\text {high }}(t)$, and $d_{1}(t), d_{2}(t)$ are the input variable, the output variable and the control variables respectively. $i_{\mathrm{L} 1}(t), i_{\mathrm{L} 2}(t), u_{\mathrm{C} 1}(t), u_{\mathrm{C} 2}(t)$ and $u_{\mathrm{C} 3}(t)$ are the state variables. When $S_{1} S_{2}=10$, the converter operates in Mode I (as shown in Fig. 3(a)), and its operating time is $d_{1}(t) \times T_{\mathrm{s}}$. So, the state space average model can be obtained as follows

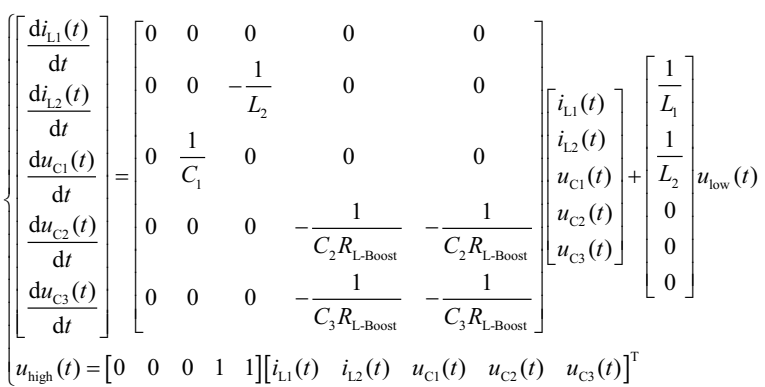

where $R_{\mathrm{L}-\text { Boost }}$ is the equivalent load resistance in the step-up mode. When $S_{1} S_{2}=00$, the converter is operating in Mode II (as shown in Fig. 3(b)), and its operating time is $\left[1-d_{1}(t)-d_{2}(t)\right] \times T_{\mathrm{s}}$. The state space average model can be written as

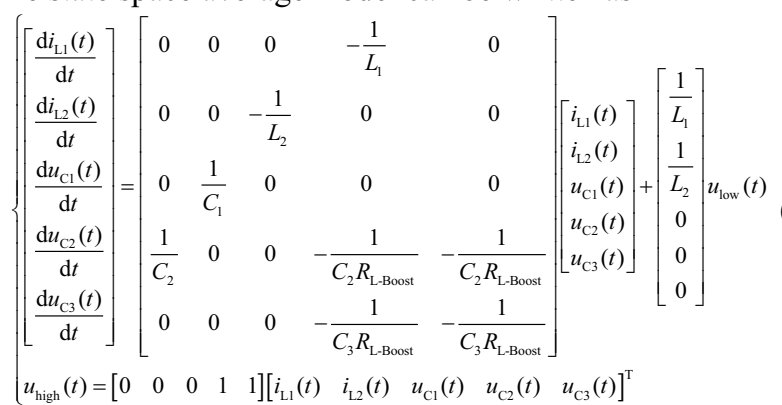

When $S_{1} S_{2}=01$, the converter operates in Mode III (as shown in Fig. 3(c)), and its operating time is $d_{2}(t) \times T_{\mathrm{s}}$. The state space average model can be achieved as

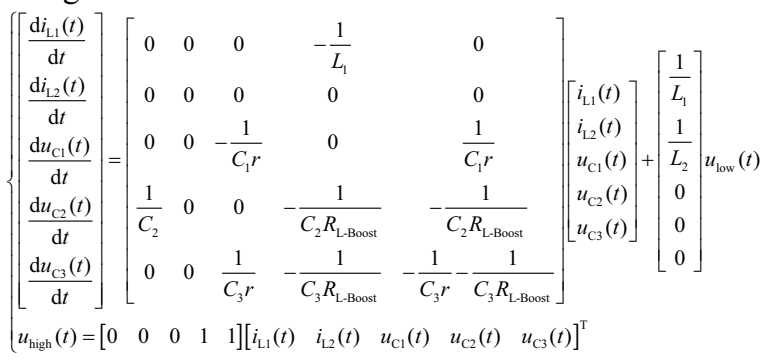

Combining (22) and (23) with (24), the average model of the converter can be obtained as:

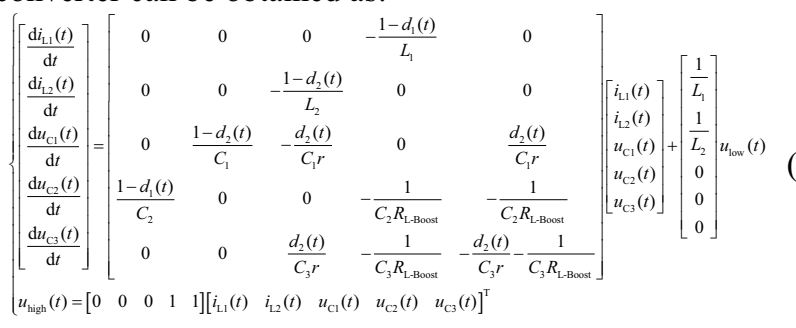

In the duty cycle range $0.5<d_{\text {Boost }}<1$, the main power semiconductors $Q_{1}$ and $Q_{2}$ also have three effective switching 
states: $S_{1} S_{2}=[10,11,01]$, and the converter is operating in Mode I, Mode IV and Mode III (as shown in Fig. 3). Their corresponding operating times are $\left[1-d_{2}(t)\right] \times T_{\mathrm{s}}$, $\left[d_{1}(t)+d_{2}(t)-1\right] \times T_{\mathrm{s}}$ and $\left[1-d_{1}(t)\right] \times T_{\mathrm{s}}$, respectively. Similarly, the corresponding average model of the proposed converter within the duty cycle range $0.5 \leq d_{\text {Boost }}<1$ can also be obtained, which is the same as that within the duty cycle range $0<d_{\text {Boost }}<0.5$. Assuming that $d_{1}=d_{2}=d_{\text {Boost, }}$, the state variables, the input variable, the output variable and the control variable can be described by using the small-signal disturbance variables as:

$$
\left\{\begin{array}{l}
i_{\mathrm{L} 1}(t)=I_{\mathrm{L} 1}+\hat{i}_{\mathrm{L} 1}(t) \\
i_{\mathrm{L} 2}(t)=I_{\mathrm{L} 2}+\hat{i}_{\mathrm{L} 2}(t) \\
u_{\mathrm{C} 1}(t)=U_{\mathrm{C} 1}+\hat{u}_{\mathrm{C} 1}(t) \\
u_{\mathrm{C} 2}(t)=U_{\mathrm{C} 2}+\hat{u}_{\mathrm{C} 2}(t) \\
u_{\mathrm{C} 3}(t)=U_{\mathrm{C} 3}+\hat{u}_{\mathrm{C} 3}(t) \\
u_{\text {low }}(t)=U_{\text {low }}+\hat{u}_{\text {low }}(t) \\
u_{\text {high }}(t)=U_{\text {high }}+\hat{u}_{\text {high }}(t) \\
d_{1}(t)=d_{2}(t)=d_{\text {Boost }}(t)=D_{\text {Boost }}+\hat{d}_{\text {Boost }}(t)
\end{array}\right.
$$

where $I_{\mathrm{L} 1}, I_{\mathrm{L} 2}, U_{\mathrm{C} 1}, U_{\mathrm{C} 2}, U_{\mathrm{C} 3}, U_{\text {low }}, U_{\text {high }}$ and $D_{\mathrm{Boost}}$ are the steady state components, $\hat{i}_{\mathrm{L} 1}(t), \hat{i}_{\mathrm{L} 2}(t), \hat{u}_{\mathrm{C} 1}(t), \hat{u}_{\mathrm{C} 2}(t), \hat{u}_{\mathrm{C} 3}(t), \hat{u}_{\mathrm{low}}(t)$, $\hat{u}_{\text {high }}(t)$ and $\hat{d}_{\text {Boost }}(t)$ are the corresponding small-signal disturbance variables. As a result, the small-signal model of the converter can be written as

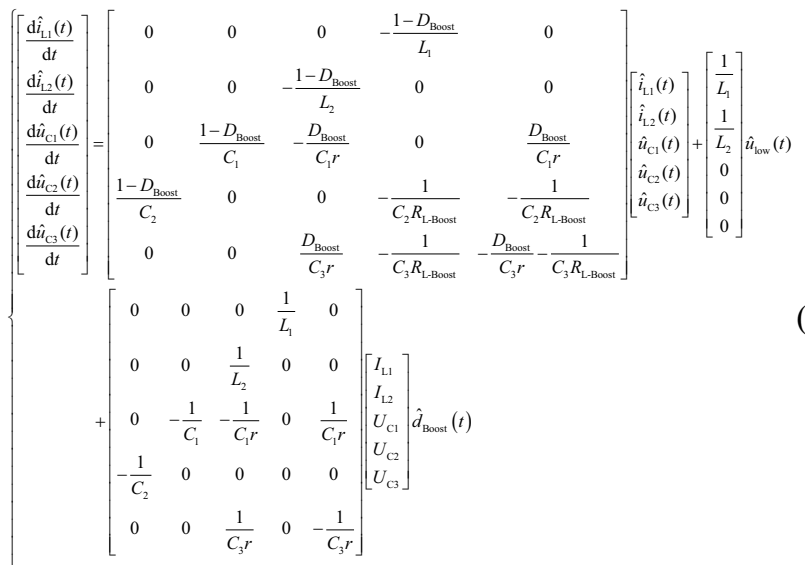

$\hat{u}_{\text {high }}(t)=\left[\begin{array}{lllll}0 & 0 & 0 & 1 & 1\end{array}\right]\left[\begin{array}{lllll}\hat{i}_{\mathrm{L} 1}(t) & \hat{i}_{\mathrm{L} 2}(t) & \hat{u}_{\mathrm{Cl}}(t) & \hat{u}_{\mathrm{C} 2}(t) & \hat{u}_{\mathrm{C} 3}(t)\end{array}\right]^{\mathrm{T}}$

According to (27) and the experimental parameters in Tab. 2, when the input voltage is $U_{\text {low }}=50 \mathrm{~V}$, the control-to-output transfer function in the step-up mode can be achieved from the time domain to the complex frequency domain as

$$
\begin{aligned}
& G_{u_{\text {him }} d_{\text {Boost }}}(s)=\left.\frac{\hat{u}_{\text {high }}(s)}{\hat{d}_{\text {Boost }}(s)}\right|_{\hat{u}_{u_{\text {low }}(s)=0}} \\
& =\frac{-2.6 \times 10^{-11} s^{4}-1.2 \times 10^{-7} s^{3}+7 \times 10^{-3} s^{2}+1.5 \times 10^{-2} s+1597}{1.3 \times 10^{-15} s^{5}+1.7 \times 10^{-11} s^{4}+1.2 \times 10^{-9} s^{3}+8.7 \times 10^{-6} s^{2}+2.3 \times 10^{-4} s+1}
\end{aligned}
$$$$
\text { (2) Small-signal modeling in the step-down mode }
$$

When the proposed bidirectional converter operates in the step-down mode in the duty cycle range $0<d_{\text {Buck }}<0.5$, the main power semiconductors $Q_{3}, Q_{4}$ and $Q_{5}$ have three effective switching states: $S_{3} S_{4} S_{5}=[100,001,011] . u_{\text {high }}(t), u_{\text {low }}(t)$, and $d_{3}(t), d_{4}(t), d_{5}(t)$ are the input variable, the output variable and the control variables respectively. $i_{\mathrm{L} 1}(t), i_{\mathrm{L} 2}(t), u_{\mathrm{C} 1}(t), u_{\mathrm{C} 2}(t)$ and $u_{\mathrm{C} 3}(t)$ are the state variables. In addition, $C_{2}$ and $C_{3}$ are connected in series, then connected with the DC source $U_{\text {high }}$ in parallel. So, the equivalent series resistance (e.g. $r_{1}=0.1 \Omega$ for the DC source $U_{\text {high }}$ ) is considered to avoid the invalid state variables. When $S_{3} S_{4} S_{5}=100$, the converter is operating in Mode I (as shown in Fig. 5(a)), and its operating time is $d_{3}(t) \times T_{\mathrm{s}}$. The state space average model can be obtained as follows

$\left[\begin{array}{c}\frac{\mathrm{d} i_{\mathrm{L} 1}(t)}{\mathrm{d} t} \\ \frac{\mathrm{d} i_{\mathrm{L} 2}(t)}{\mathrm{d} t} \\ \frac{\mathrm{d} u_{\mathrm{Cl}}(t)}{\mathrm{d} t} \\ \frac{\mathrm{d} u_{\mathrm{C} 2}(t)}{\mathrm{d} t} \\ \frac{\mathrm{d} u_{\mathrm{CS}}(t)}{\mathrm{d} t} \\ \frac{\mathrm{d} u_{\text {low }}(t)}{\mathrm{d} t}\end{array}\right]=\left[\begin{array}{cccccc}0 & 0 & 0 & 0 & 0 & -\frac{1}{L_{1}} \\ 0 & 0 & \frac{1}{L_{2}} & 0 & 0 & -\frac{1}{L_{2}} \\ 0 & -\frac{1}{C_{1}} & 0 & 0 & 0 & 0 \\ 0 & 0 & 0 & -\frac{1}{C_{2} r_{1}} & -\frac{1}{C_{2} r_{1}} & 0 \\ 0 & 0 & 0 & -\frac{1}{C_{3} r_{1}} & -\frac{1}{C_{3} r_{1}} & 0 \\ \frac{1}{C_{\text {low }}} & \frac{1}{C_{\text {low }}} & 0 & 0 & 0 & -\frac{1}{R_{\mathrm{L} \text { - Buck }} C_{\text {low }}}\end{array}\right]\left[\begin{array}{c}i_{\mathrm{LL}}(t) \\ \mathrm{L}_{22}(t) \\ u_{\mathrm{Cl}}(t) \\ u_{\mathrm{C} 2}(t) \\ u_{\mathrm{C} 3}(t) \\ u_{\text {low }}(t)\end{array}\right]+\left[\begin{array}{c}0 \\ 0 \\ 0 \\ \frac{1}{C_{2} r_{1}} \\ \frac{1}{C_{3} r_{1}} \\ 0\end{array}\right] u_{\text {high }}(t)$

where $R_{\mathrm{L}-\mathrm{Buck}}$ is the equivalent load resistance in the step-down mode. When $S_{3} S_{4} S_{5}=011$, the converter operates in Mode III (as shown in Fig. 5(c)), and its operating time is $d_{4}(t) \times T_{\mathrm{s}}$. So, the state space average model can be written as

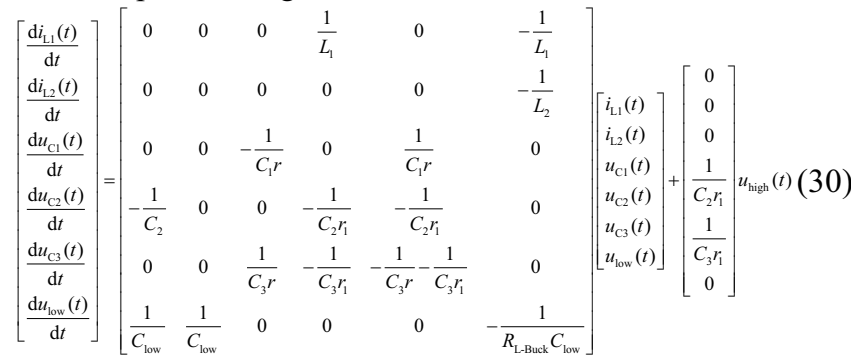

When $S_{3} S_{4} S_{5}=001$, the converter is operating in Mode IV (as shown in Fig. 5(d)), and its operating time is $\left[1-d_{3}(t)-d_{4}(t)\right] \times T_{\mathrm{s}}$. The state space average model can be achieved as

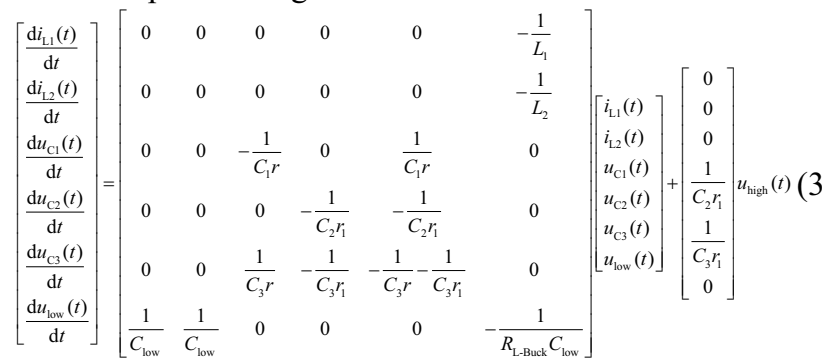

Combining (29), and (30) with (31), the average model of the converter can be obtained as:

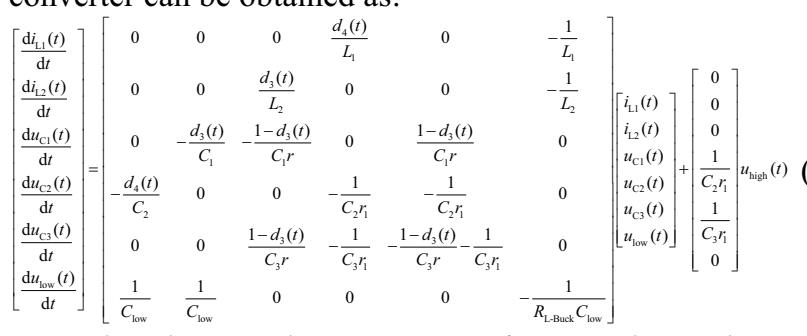

In the duty cycle range $0.5<d_{\mathrm{Buck}}<1$, the main power semiconductors $Q_{3}, Q_{4}$ and $Q_{5}$ also have three effective switching states: $S_{3} S_{4} S_{5}=[100,110,011]$, the converter is operating in Mode I, Mode II and Mode III (as shown in Fig. 
5), and their operating times are $\left[1-d_{4}(t)\right] \times T_{\mathrm{s}}$, $\left[d_{3}(t)+d_{4}(t)-1\right] \times T_{\mathrm{s}}$ and $\left[1-d_{3}(t)\right] \times T_{\mathrm{s}}$, respectively. In a similar way, the corresponding average models of the proposed converter within the duty cycle range $0.5 \leq d_{\text {Buck }}<1$ can also be obtained, which are the same as those within the duty cycle range $0<d_{\text {Buck }}<0.5$. Assuming that $d_{3}=d_{4}=d_{\text {Buck, }}$ the state variables, the input variable, the output variable and the control variables can be described by using the small-signal disturbance variables as:

$$
\left\{\begin{array}{l}
i_{\mathrm{L} 1}(t)=I_{\mathrm{L} 1}+\hat{i}_{\mathrm{L} 1}(t) \\
i_{\mathrm{L} 2}(t)=I_{\mathrm{L} 2}+\hat{i}_{\mathrm{L} 2}(t) \\
u_{\mathrm{C} 1}(t)=U_{\mathrm{C} 1}+\hat{u}_{\mathrm{C} 1}(t) \\
u_{\mathrm{C} 2}(t)=U_{\mathrm{C} 2}+\hat{u}_{\mathrm{C} 2}(t) \\
u_{\mathrm{C} 3}(t)=U_{\mathrm{C} 3}+\hat{u}_{\mathrm{C} 3}(t) \\
u_{\text {high }}(t)=U_{\text {high }}+\hat{u}_{\text {high }}(t) \\
u_{\text {low }}(t)=U_{\text {low }}+\hat{u}_{\text {low }}(t) \\
d_{3}(t)=d_{4}(t)=d_{\text {Buck }}(t)=D_{\text {Buck }}+\hat{d}_{\text {Buck }}(t)
\end{array}\right.
$$

where $I_{\mathrm{L} 1}, I_{\mathrm{L} 2}, U_{\mathrm{C} 1}, U_{\mathrm{C} 2}, U_{\mathrm{C} 3}, U_{\text {high }}, U_{\text {low }}$ and $D_{\text {Buck }}$ are the steady state components, $\hat{i}_{\mathrm{L} 1}(t), \hat{i}_{\mathrm{L} 2}(t), \hat{u}_{\mathrm{C} 1}(t), \hat{u}_{\mathrm{C} 2}(t), \hat{u}_{\mathrm{c} 3}(t), \hat{u}_{\text {high }}(t)$ $\hat{u}_{\text {low }}(t)$ and $\hat{d}_{\text {Buck }}(t)$ are the corresponding small-signal disturbance variables. As a result, the small-signal model of the converter can be written as

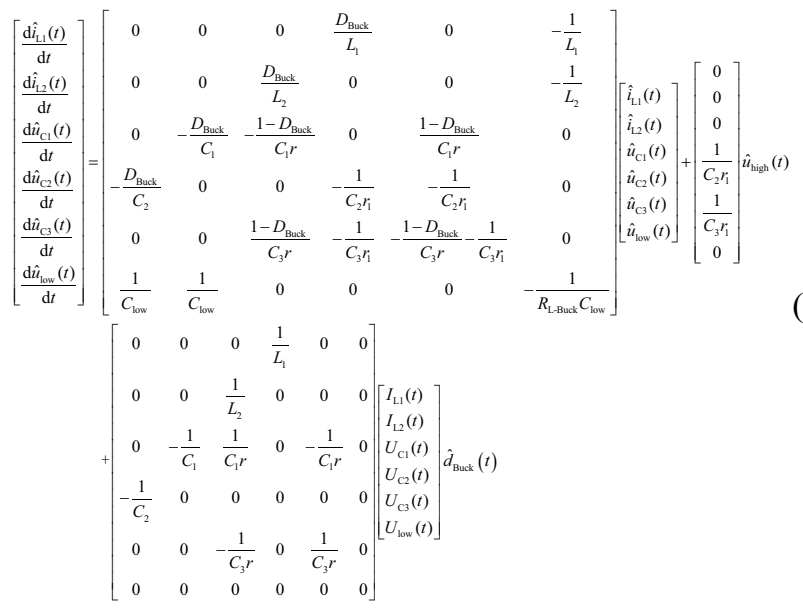

In terms of (34) and the experimental parameters in Tab. 2, when the output voltage is $U_{\text {low }}=50 \mathrm{~V}$, the control-to-output transfer function in the step-down mode can be achieved from the time domain to the complex frequency domain as

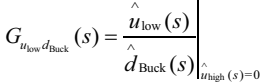

$$
\begin{aligned}
& 2.4 \times 10^{-12} s^{4}+1.2 \times 10^{-7} s^{3}+8.7 \times 10^{-4} s^{2}+3.1 \times 10^{-2} s+199 \\
& =\frac{1.1 \times 10^{-21} s^{6}+5.7 \times 10^{-17} s^{5}+4.5 \times 10^{-13} s^{4}+9.5 \times 10^{-10} s^{3}+4.5 \times 10^{-6} s^{2}+2.3 \times 10^{-4} s+1}{10}
\end{aligned}
$$

\section{EXPERIMENTAL RESULTS AND AYALYSIS}

In order to verify the feasibility of the proposed converter, a $1 \mathrm{~kW}$ experimental prototype of the interleaved switched-capacitor bidirectional DC-DC converter is developed, which is shown in Fig. 9. The experiment parameters are shown in Tab. 2.

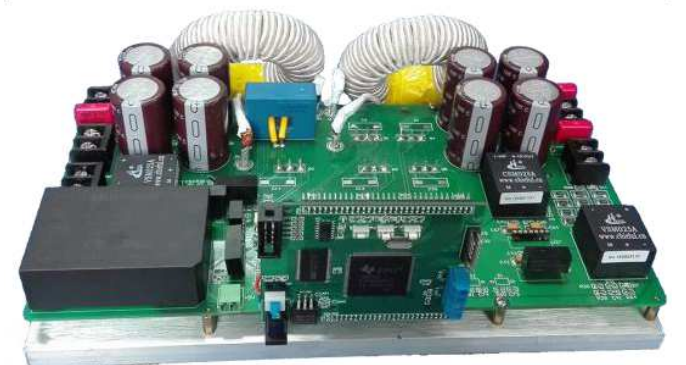

Fig. 9 The experimental prototype of the interleaved switched-capacitor bidirectional DC-DC converter.

Tab. 2 Experiment parameters.

\begin{tabular}{cc}
\hline Parameters & Values \\
\hline Rated power $P_{\mathrm{n}}$ & $1 \mathrm{~kW}$ \\
Storage/filter capacitor $C_{\text {low }}$ & $520 \mu \mathrm{F}$ \\
Switched-capacitors $C_{1}, C_{2}$ and $C_{3}$ & $520 \mu \mathrm{F}$ \\
Storage/filter inductor $L_{1}$ & $353 \mu \mathrm{H}$ \\
Storage/filter inductor $L_{2}$ & $347 \mu \mathrm{H}$ \\
High voltage side $U_{\text {high }}$ & $400 \mathrm{~V}$ \\
Low voltage side $U_{\text {low }}$ & $50 \sim 120 \mathrm{~V}$ \\
Switching frequency $f_{\mathrm{s}}$ & $20 \mathrm{kHz}$ \\
Power semiconductors $Q_{1} \sim Q_{5}$ & IXTK $102 \mathrm{~N} 30 \mathrm{P}$ \\
\hline
\end{tabular}

\section{A. Experimental results in the step-up mode}

The voltage waveforms of the main and slave power semiconductors of the proposed converter in the step-up operation mode are shown in Fig. 10 and Fig. 11, respectively. The PWM voltage of each power semiconductors is $200 \mathrm{~V}$, namely half of $U_{\text {high, }}$ which validates the analysis in Section IV. In addition, the current flows through the anti-parallel diodes of $Q_{3}, Q_{4}$ and $Q_{5}$ during the dead time, and the blocking voltages of $Q_{3}, Q_{4}$ and $Q_{5}$ are around zero. Otherwise, the controlled MOSFETs $Q_{3}, Q_{4}$ and $Q_{5}$ are turned on and turned off with ZVS by the synchronous rectification, e.g. the gate signal $S_{4}$ and the voltage stress of $Q_{4}$ as shown in Fig. 11.

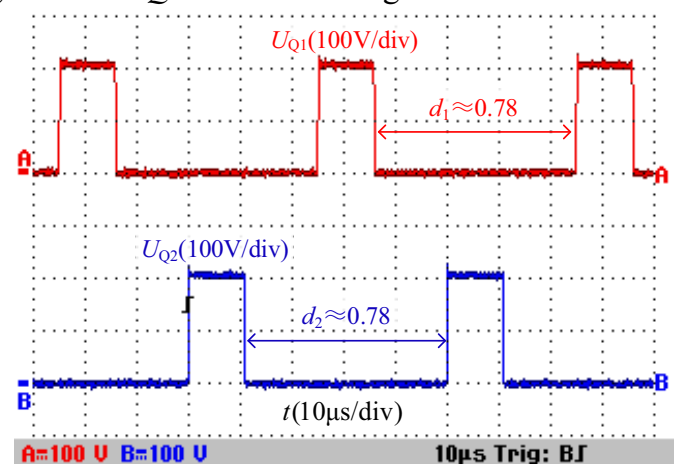

Fig. 10 The PWM voltages of power semiconductors $Q_{1}$ and $Q_{2}$.

When the input voltage is $U_{\text {low }}=50 \mathrm{~V}$, the output voltage $U_{\text {high }}$ and the voltage across $C_{3}$ are shown in Fig. 12. According to Fig. 12 , the voltage across $C_{3}$ is $200 \mathrm{~V}$ (i.e. half of the output voltage). In addition, the potential difference between the input and output side grounds of this converter is just the voltage across $C_{3}$ (i.e. the constant voltage $200 \mathrm{~V}$ with very small ripple), rather than the PWM voltage.

The input and inductor currents of the proposed converter in the step-up operation mode are shown in Fig. 13. The inductor currents $i_{\mathrm{L} 1}$ and $i_{\mathrm{L} 2}$ are shown in Fig. 13(a). Fig. 13(b) shows the 
input current $i_{\text {low }}$ and the inductor current $i_{\mathrm{L} 1}$. According to Fig. 13 , the current ripple rates of $i_{\mathrm{L} 1}$ and $i_{\mathrm{L} 2}$ are about $49 \%$, and the current ripple rate of the input current is only $17.6 \%$. According to (19), the ripple rate of $i_{\mathrm{L} 1}$ and $i_{\mathrm{L} 2}$ is $53.57 \%$, and the current ripple rate of $i_{\text {low }}$ is $17.86 \%$ theoretically, which agree with the experimental results. The conclusion that the current ripple of $i_{\text {low }}$ is much lower than the current ripple of $i_{\mathrm{L} 1}$ and $i_{\mathrm{L} 2}$ can be obtained.

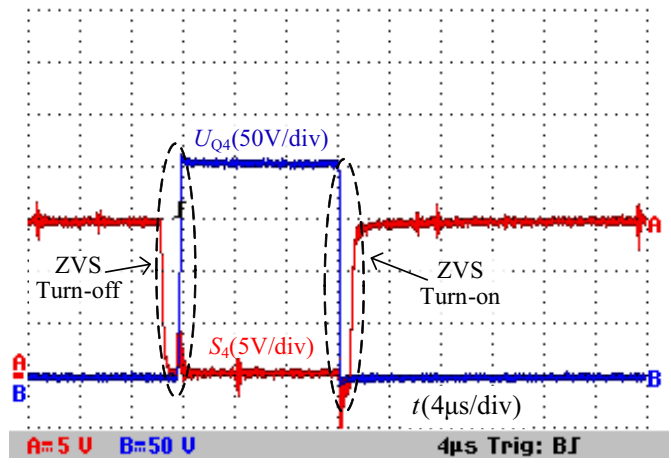

Fig. 11 Gate signal and voltage stress across synchronous rectification power switch $Q_{4}$.

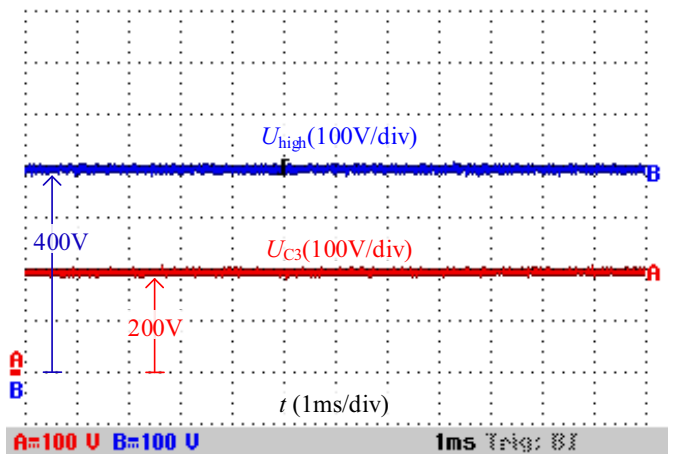

Fig. 12 Voltages $U_{\text {high }}$ and $U_{\mathrm{C} 3}$ when the input voltage is $U_{\text {low }}=50 \mathrm{~V}$.

The input and capacitor current waveforms of the proposed converter operating in the step-up mode are shown in Fig. 14, when the input voltage is $U_{\text {low }}=50 \mathrm{~V}$ and the output voltage is $U_{\text {high }}=400 \mathrm{~V}$. From Fig. 14, it can be observed that the amplitude of $i_{\mathrm{C} 1}$ is higher than those of $i_{\mathrm{C} 2}$ and $i_{\mathrm{C} 3}$, and the maximum charge current of $C_{1}$ is nearly equal to half of that of $i_{\text {low. }}$. According to Fig. 3(a), the current flowing through $Q_{3}$ is the charging current of $C_{1}$. Thus, the conclusion that the current stress of $Q_{3}$ is reduced to half of the input current can be obtained, which agrees with the theoretical analysis previously mentioned in (16). Besides, the average amplitude of the charging or the discharging current of $C_{3}$ is the smallest one (less than 2A), which is conducive to reduce the voltage fluctuations between the input and output side grounds of this converter.

In the step-up mode, the output voltage can stay constant around the reference voltage $400 \mathrm{~V}$ with the action of the voltage control loop. Fig. 15 illustrates the dynamical responses of the output voltage and the input voltage when the input voltage is changed from $120 \mathrm{~V}$ to $50 \mathrm{~V}$ continuously. According to Fig. 15, when the input voltage $U_{\text {low }}$ varies continuously from $120 \mathrm{~V}$ to $50 \mathrm{~V}$, the output voltage still stays around $400 \mathrm{~V}$, which means the proposed converter can obtain a wide voltage-gain range varying from 3.3 to 8 .

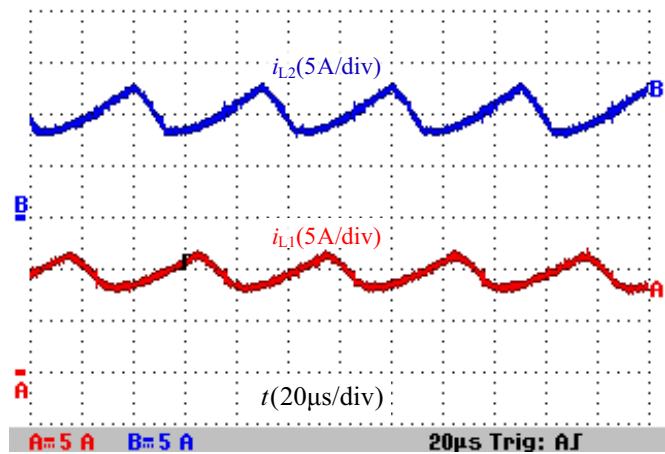

(a)

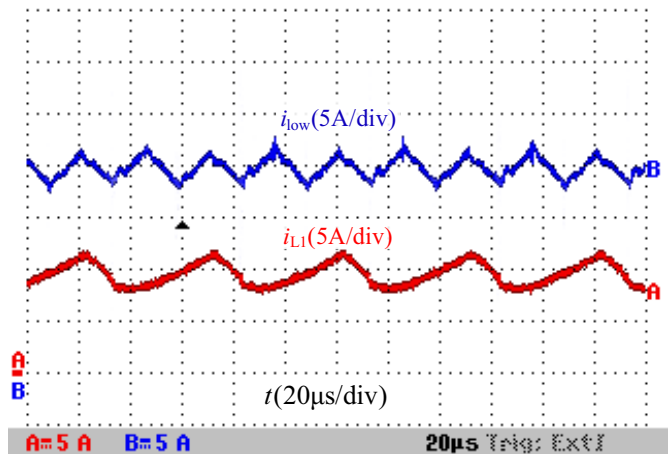

(b)

Fig. 13 The input current $i_{\text {low }}$, inductor currents $i_{\mathrm{L} 1}$ and $i_{\mathrm{L} 2}$ when the input voltage is $U_{\text {low }}=50 \mathrm{~V}$ and the output voltage is $U_{\text {high }}=400 \mathrm{~V}$. (a) Inductor currents $i_{\mathrm{L} 1}$ and $i_{\mathrm{L} 2}$. (b) The input current $i_{\text {low }}$ and the inductor current $i_{\mathrm{L} 1}$.

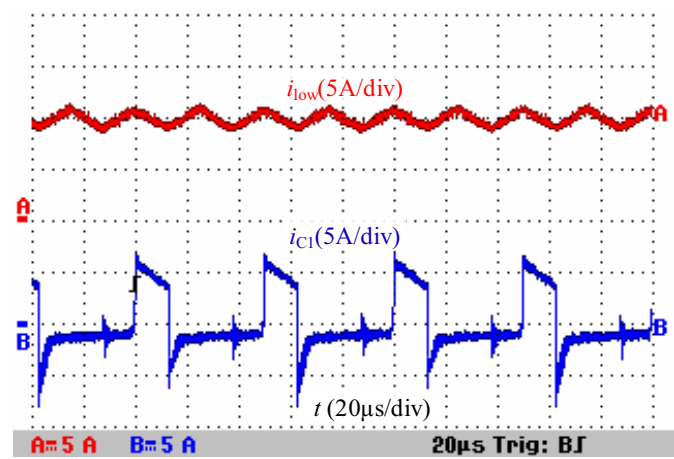

(a)

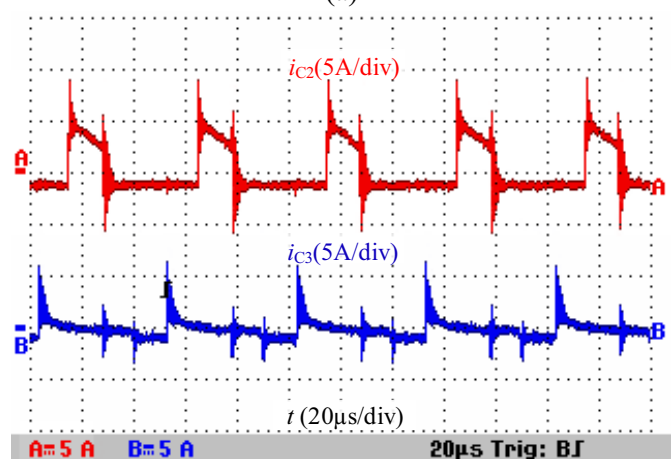

(b)

Fig. 14 The input current $i_{\text {low }}$, capacitor currents $i_{\mathrm{C} 1}, i_{\mathrm{C} 2}$ and $i_{\mathrm{C} 3}$ in the step-up mode. (a) The input current $i_{\text {low }}$ and the capacitor current $i_{\mathrm{Cl}}$. (b) Capacitor currents $i_{\mathrm{C} 2}$ and $i_{\mathrm{C} 3}$. 


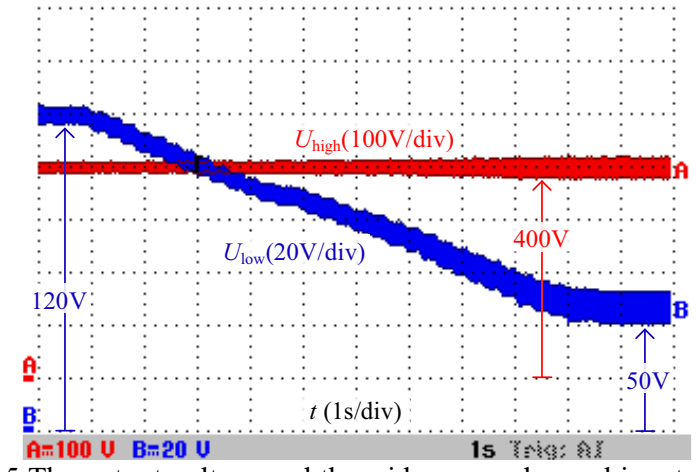

Fig. 15 The output voltage and the wide-range changed input voltage from $120 \mathrm{~V}$ to $50 \mathrm{~V}$ in the step-up mode.

\section{B. Experimental results in the step-down mode}

The voltage waveforms of the main and slave power semiconductors of the proposed converter in the step-down operation mode are shown in Fig. 16 and Fig. 17 respectively. Similar to the experimental results in the step-up mode, the PWM voltage of each power semiconductors is $200 \mathrm{~V}$, which is half of the high-voltage side $U_{\text {high }}$. In addition, the slave power semiconductors $Q_{1}$ and $Q_{2}$ are also turned on and turned off with ZVS in the synchronous rectification operation, and the gate signal $S_{1}$ and the voltage stress of $Q_{1}$ are shown in Fig. 17.

When the output voltage is $U_{\text {low }}=50 \mathrm{~V}$, the input voltage $U_{\text {high }}$ and the voltage across $C_{3}$ are shown in Fig. 18. According to Fig. 18 , the voltage across $C_{3}$ is also at constant $200 \mathrm{~V}$ (i.e. half of the output voltage). In addition, the potential difference $U_{\mathrm{C} 3}$ between the input and output side grounds of this converter also has a very small ripple and $\mathrm{d} v / \mathrm{d} t$, which is the same as that in the step-up mode.

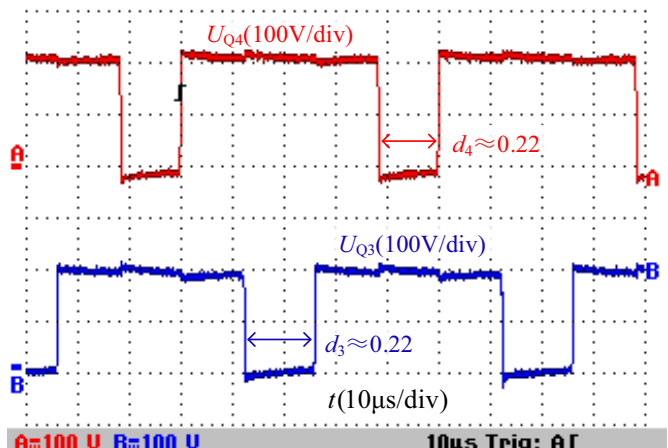

Fig. 16 The PWM voltages of power semiconductors $Q_{3}$ and $Q_{4}$.

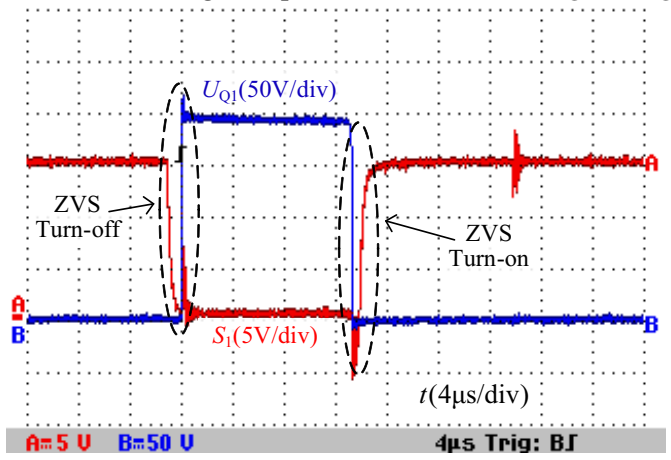

Fig. 17 Gate signal and voltage stress of synchronous rectification power semiconductor $Q_{1}$.

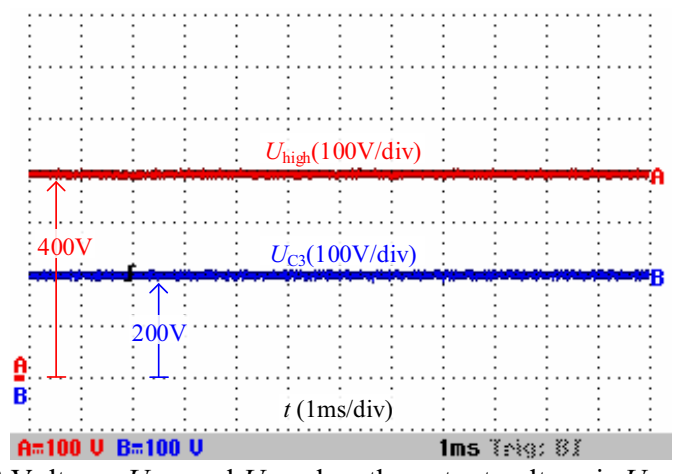

Fig. 18 Voltages $U_{\text {high }}$ and $U_{\mathrm{C} 3}$ when the output voltage is $U_{\text {low }}=50 \mathrm{~V}$.

The output and inductor current waveforms of the proposed converter in the step-down operation mode are shown in Fig. 19. The inductor currents $i_{\mathrm{L} 1}$ and $i_{\mathrm{L} 2}$ are shown in Fig. 19(a). Fig. 19(b) shows the output current $i_{\text {low }}$ and the inductor current $i_{\mathrm{L} 1}$. According to Fig. 19, the current ripple rate of $i_{\mathrm{L} 1}$ is $46 \%$, and the current ripple rate of $i_{\mathrm{L} 2}$ is $50.6 \%$. In addition, the current ripple rate of the output current is $17.65 \%$. According to (20), the ripple rate of $i_{\mathrm{L} 1}$ and $i_{\mathrm{L} 2}$ is $53.57 \%$, and the ripple rate of $i_{\text {low }}$ is $17.86 \%$ theoretically, which are in accordance with the experimental results. The conclusion that the current ripple of $i_{\text {low }}$ is much lower than the current ripple of $i_{\mathrm{L} 1}$ and $i_{\mathrm{L} 2}$ can be obtained.

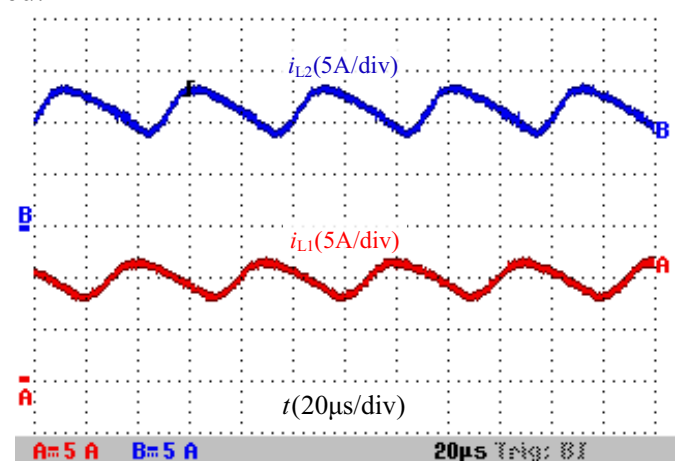

(a)

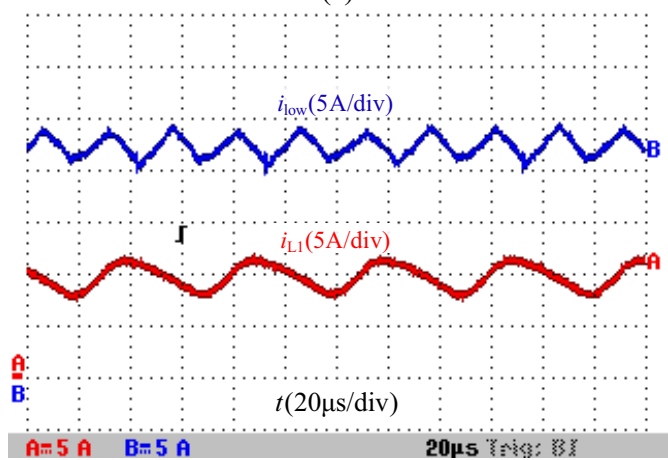

(b)

Fig. 19 The output current $i_{\text {low }}$, inductor currents $i_{\mathrm{L} 1}$ and $i_{\mathrm{L} 2}$ when the output voltage is $U_{\text {low }}=50 \mathrm{~V}$ and the input voltage is $U_{\text {high }}=400 \mathrm{~V}$. (a) Inductor currents $i_{\mathrm{L} 1}$ and $i_{\mathrm{L} 2}$. (b) The output current $i_{\text {low }}$ and the inductor current $i_{\mathrm{L} 1}$.

Fig. 20 shows the output and capacitor current waveforms of the proposed converter in the step-down mode, when the input voltage is $U_{\text {high }}=400 \mathrm{~V}$ and the output voltage is $U_{\text {low }}=50 \mathrm{~V}$. From Fig. 20, it can be seen that the amplitude of $i_{\mathrm{Cl}}$ is also higher than those of $i_{\mathrm{C} 2}$ and $i_{\mathrm{C} 3}$, and the maximum discharging current of $C_{1}$ 
is also nearly equal to half of that of $i_{\text {low. }}$ According to Fig. 5(a), the current flowing through $Q_{3}$ is the discharging current of $C_{1}$. Thus, the conclusion that the current stress of $Q_{3}$ is also reduced to half of the output current can be achieved, which also agrees with the theoretical analysis previously mentioned in (17). Besides, the average amplitude of the charging or the discharging current of $C_{3}$ is also the smallest one (less than 2A), which is the same as that in the step-up mode.

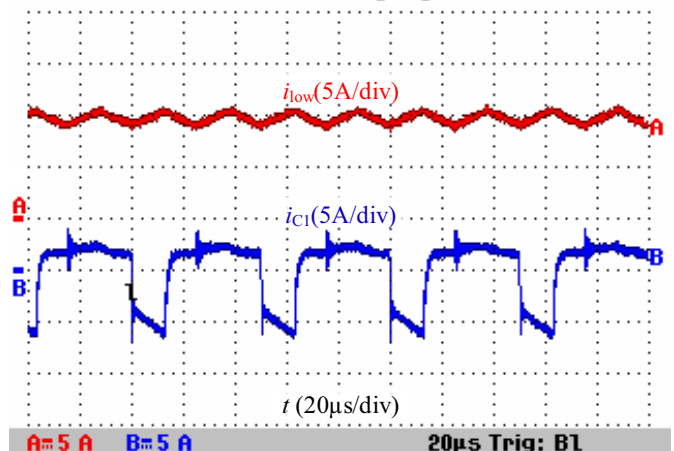

(a)

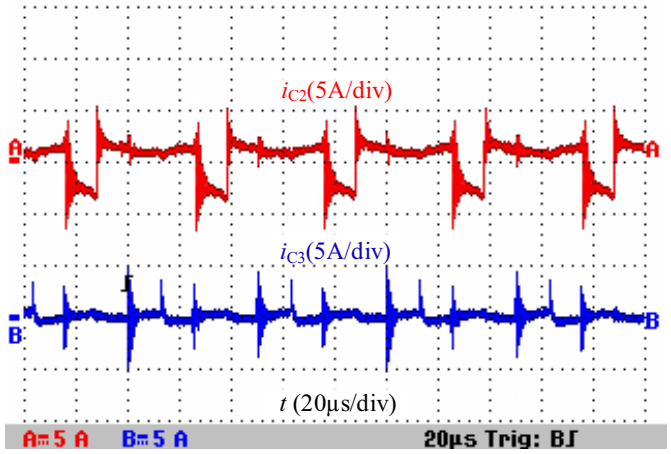

(b)

Fig. 20 The output current $i_{\text {low }}$, capacitor currents $i_{\mathrm{C} 1}, i_{\mathrm{C} 2}$ and $i_{\mathrm{C} 3}$ in the step-down mode. (a) The output current $i_{\text {low }}$ and the capacitor current $i_{\mathrm{C} 1}$. (b) Capacitor currents $i_{\mathrm{C} 2}$ and $i_{\mathrm{C} 3}$.

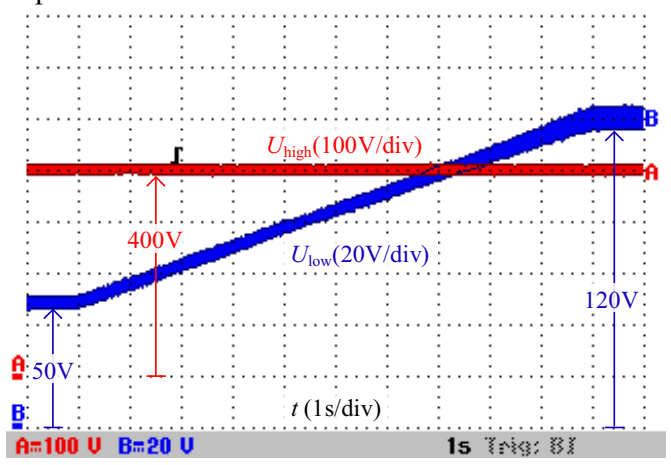

Fig. 21 The input voltage and the wide-range changed output voltage from $50 \mathrm{~V}$ to $120 \mathrm{~V}$ in the step-down mode.

Fig. 21 can be used to validate the converter's function of charging the super-capacitors or the batteries. According to Fig. 21 , when the input voltage stays around $400 \mathrm{~V}$, the output voltage $U_{\text {low }}$ varies continuously from $50 \mathrm{~V}$ to $120 \mathrm{~V}$ under the control of the voltage loop (i.e. a PI controller), in which the reference voltage is adjusted from $50 \mathrm{~V}$ to $120 \mathrm{~V}$ over 10 seconds, while the input voltage keeps at $400 \mathrm{~V}$. Therefore, it means the proposed converter can obtain a wide voltage-gain range varying from $1 / 8$ to $1 / 3.3$, and it can charge the super-capacitors or the batteries in a wide terminal voltage range.

\section{Bidirectional power flow experiment}

Fig. 22 shows the hybrid energy sources storage system, where the super-capacitor bank adopts the super-capacitor of CSDWELL's model MODWJ001PM031Z2. In addition, the battery in the hybrid energy sources is a lithium iron phosphate battery with the rated voltage of $48 \mathrm{~V}$. The experimental results of the bidirectional power flow control are shown in Fig. 23.

In the hybrid energy storage sources system shown in Fig. 22, $U_{\mathrm{dc}}$ is the DC bus voltage, $U_{\mathrm{bat}}$ and $I_{\mathrm{bat}}$ are the output voltage and output current of the battery, $U_{\mathrm{sc}}$ and $I_{\mathrm{sc}}$ are the output voltage and output current of the super-capacitor, and $I_{\mathrm{dc}}$ is the load current. In the experiment of the bidirectional power flow control, the output voltage of the battery is about $50 \mathrm{~V}$, the output voltage of the super-capacitor is around $40 \mathrm{~V}$, and the DC bus power varies with the step changes from $400 \mathrm{~W}$ to $650 \mathrm{~W}$. The interleaved switched-capacitor bidirectional DC-DC converter proposed in this paper is applied to interface the super-capacitor and the DC bus, and it operates according to the control strategy shown in Fig. 7.

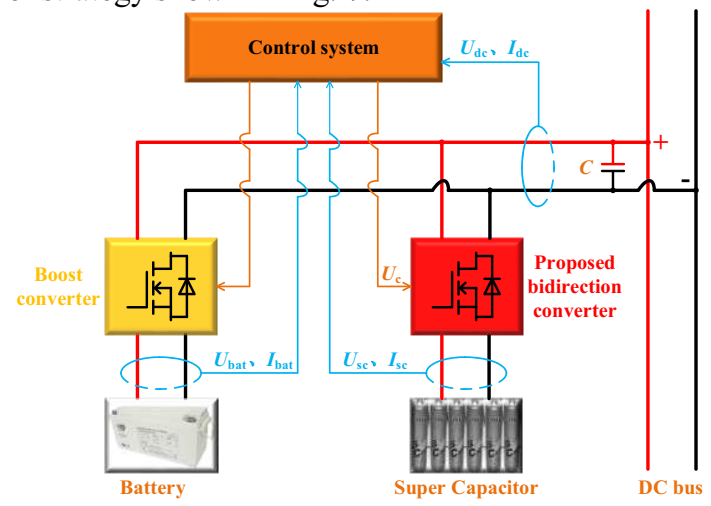

Fig. 22 Hybrid energy sources storage system.

Fig. 23 shows the variations of $i_{\text {bat }}$ and $i_{\mathrm{sc}}$ during the sudden increase and decrease in the loads of the proposed bidirectional converter, when super-capacitors are operating. According to Fig. 23, when the power required by the DC bus is changed from $400 \mathrm{~W}$ to $650 \mathrm{~W}$ with a step change, the control system sets the control signal $U_{\mathrm{c}}$ to "zero". At the same time, the proposed switched-capacitor bidirectional converter responds quickly and operates in the step-up mode. The current $I_{\mathrm{sc}}$ increases from zero to $6 \mathrm{~A}$ in $20 \mathrm{~ms}$ approximately, and the instantaneous power provided by the super-capacitor is nearly equal to the required power change of the DC bus, avoiding the step change current from the battery, which may shorten the life of the battery. As a result, the current of the battery rises from $8 \mathrm{~A}$ to $13 \mathrm{~A}$ gradually, and the current of the super-capacitor falls to zero from $I_{\mathrm{sc}}=6 \mathrm{~A}$. Similarly, when the power required by the DC bus is changed from $650 \mathrm{~W}$ to $400 \mathrm{~W}$ with a step change, the control system sets the control signal $U_{\mathrm{c}}$ to "1". At the same time, the proposed switched-capacitor bidirectional converter responds quickly and operates in the step-down mode. The current $I_{\mathrm{sc}}$ increases from zero to $6 \mathrm{~A}$ with the opposite direction in $20 \mathrm{~ms}$ approximately. As a result, the current from the battery falls from $13 \mathrm{~A}$ to $8 \mathrm{~A}$ gradually, and the current of the super-capacitor falls to zero from $I_{\mathrm{sc}}=-6 \mathrm{~A}$. 
Fig. 24 shows the variations of $i_{\text {bat }}$ and $i_{\mathrm{sc}}$ with the same load step change, when super-capacitors are not operating. According to Fig. 24, when the DC bus demand power is changed from $400 \mathrm{~W}$ to $650 \mathrm{~W}$ with a step change, the current $I_{\text {bat }}$ quickly increases from $8 \mathrm{~A}$ to $13 \mathrm{~A}$ with a step change. When the DC bus demand power is changed from $650 \mathrm{~W}$ to $400 \mathrm{~W}$ with a step change, the current $I_{\text {bat }}$ quickly decreases from $13 \mathrm{~A}$ to $8 \mathrm{~A}$ with a step change. It is seen that when the load power varies with a step change, the battery has to tolerate the step change current, and this is easy to cause the impact on the battery itself during the process of the electric vehicle's acceleration and deceleration, and then shorten its service life.

Comparing the experimental results of Fig. 23 and Fig. 24, it is seen that when the DC bus demand power quickly increases or decreases, the proposed switched-capacitor bidirectional converter can respond quickly according to the control signal $U_{\mathrm{c}}$, and the super-capacitor can compensate (take in and send out) the power gap between the battery and the DC bus side to ensure that the current output from the battery changes more slowly and therefore, avoid reduction of the battery life.

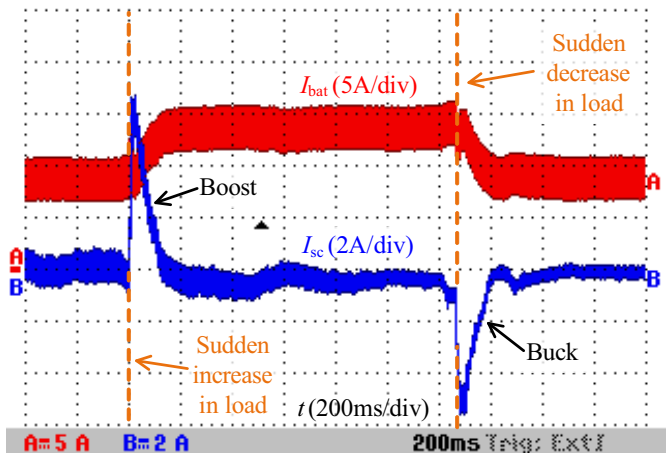

Fig. 23 Experimental results of bidirectional power flow control (super-capacitors are operating).

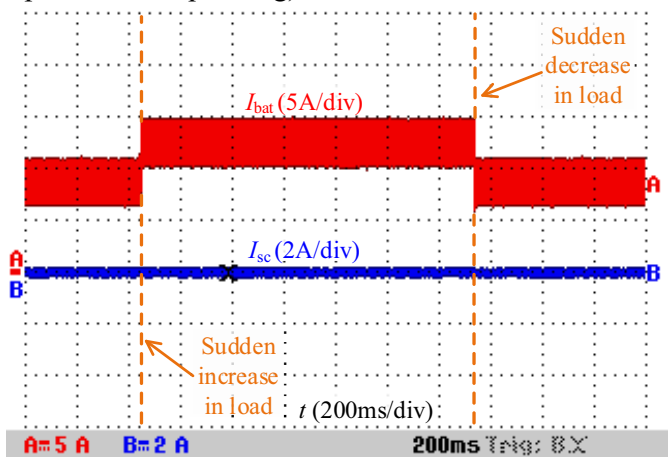

Fig. 24 Experimental results of bidirectional power flow control (super-capacitors are not operating).

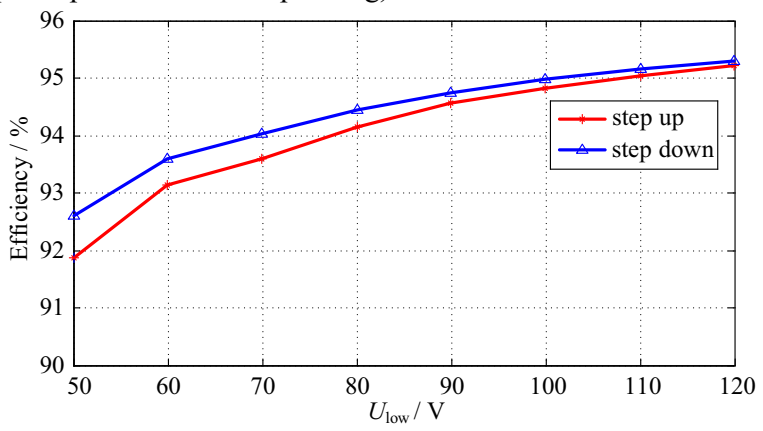

Fig. 25 Efficiencies of the proposed switched-capacitor bidirectional converter in step-up and step-down modes ( $U_{\text {high }}=400 \mathrm{~V}$, $\left.U_{\text {low }}=50 \mathrm{~V} \sim 120 \mathrm{~V}, P_{\mathrm{n}}=1 \mathrm{~kW}\right)$.

The efficiencies of the proposed bidirectional DC-DC converter in the step-up and step-down modes are shown in Fig. 25 when the high-voltage side $U_{\text {high }}$ is $400 \mathrm{~V}$ and the low-voltage side $U_{\text {low }}$ varies from $50 \mathrm{~V}$ to $120 \mathrm{~V}$ or $120 \mathrm{~V}$ to $50 \mathrm{~V}$ continuously. The efficiencies are measured by the power analyzer YOKOGAWA/WT3000. According to Fig. 25, the measured efficiencies are from $91.88 \% \quad\left(U_{\text {low }}=50 \mathrm{~V}\right)$ to $95.21 \%$ $\left(U_{\text {low }}=120 \mathrm{~V}\right)$ in the step-up mode, and from $92.60 \%\left(U_{\text {low }}=50 \mathrm{~V}\right)$ to $95.30 \%\left(U_{\text {low }}=120 \mathrm{~V}\right)$ in the step-down mode. With the constant load $P_{\mathrm{n}}=1 \mathrm{~kW}$ and $U_{\text {high }}=400 \mathrm{~V}$ in the step-up/down modes, the effective values of the low side currents increase due to the decrease of the low side voltages (i.e. the increase of the voltage-gain). Therefore, the turn-on/off losses, and the conduction losses of the power semiconductors will raise, as well as the conduction losses of the equivalent series resistors of the circuit. Moreover, the maximum efficiency arrives at $95.21 \%$ and $95.30 \%$ in the step-up and step-down modes respectively when the low-voltage side $U_{\text {low }}$ is $120 \mathrm{~V}$, and the efficiency in the step-down mode is slightly higher than that in the step-up mode.

\section{Conclusions}

In this paper, an interleaved switched-capacitor bidirectional DC-DC converter has been introduced. The proposed topology can benefit from high step-up/step-down ratio, a wide voltage-gain range and avoiding of the extreme duty cycles. In addition, this converter has the advantages of the low voltage stress of power semiconductors and capacitors, and low current ripples in the low-voltage side. Besides, the slave active power semiconductors allow ZVS turn-on and turn-off, and the efficiency of the converter is improved. The capacitor voltages and the inductor currents can be easily balanced due to the self-balance function. The proposed bidirectional DC-DC converter has good dynamic and steady-state performance and is suitable for the power interface between the low-voltage battery pack and the high-voltage DC bus for various new energy storage systems.

\section{REFERENCES}

[1] K. Sun, L. Zhang, Y. Xing, and J. M. Guerrero, "A distributed control strategy based on DC bus signaling for modular photovoltaic generation systems with battery energy storage," IEEE Trans. Power Electron., vol. 26, no. 10 , pp. 3032-3045, Oct. 2011.

[2] P. Sanchis, J. Lopez, A. Ursua, and L. Marroyo, "Electronic controlled device for the analysis and design of photovoltaic systems," IEEE Power Electron. Lett., vol. 3, no. 2, pp. 57-62, Jun. 2005.

[3] X. Lu, K. Sun, J. M. Guerrero, J. C. Vasquez, and L. Huang, "State-of-charge balance using adaptive droop control for distributed energy storage systems in DC micro-grid applications," IEEE Trans. Ind. Electron., vol. 61, no. 6, pp. 2804-2815, Jun. 2014.

[4] R. Gules, J. D. P. Pacheco, H. L. Hey, and J. Imhoff, “A maximum power point tracking system with parallel connection for PV stand-alone applications," IEEE Trans. Ind. Electron., vol. 55, no. 7, pp. 2674-2683, Jul. 2008.

[5] R. J. Wai, R. Y. Duan, and K. H. Jheng, "High-efficiency bidirectional dc-dc converter with high-voltage gain," IET Power Electron., vol. 5, no. 2, pp. 173-184, Feb. 2012.

[6] R. Y. Duan and J. D. Lee, "High-efficiency bidirectional dc-dc converter with coupled inductor," IET Power Electron., vol. 5, no. 1, pp. 115-123, Jan. 2012. 
[7] W. Li, C. Xu, H. Yu, Y. Gu, and X. He, "Analysis, design and implementation of isolated bidirectional converter with winding-cross-coupled inductors for high step-up and high step-down conversion system," IET Power Electron., vol. 7, no. 1, pp. 67-77, Jan. 2014.

[8] T. F. Wu, Y. C. Chen, J. G. Yang, and C. L. kuo, "Isolated bidirectional full-bridge dc-dc converter with a flyback snubber," IEEE Trans. Power Electron., vol. 25, no. 7, pp. 1915-1922, Jul. 2010.

[9] G. Chen, Y. S. Lee, S. Y. R. Hui, D. Xu, and Y. Wang, "Actively clamped bidirectional flyback converter," IEEE Trans. Ind. Electron., vol. 47, no. 4, pp. 770-779, Aug. 2000.

[10] A. Rodriguez, A. Vazquez, D. G. Lamar, M. M. Hernando, and J. Sebastian, "Different purpose design strategies and techniques to improve the performance of a dual active bridge with phase-shift control," IEEE Trans. Power Electron., vol. 30, no. 2, pp. 790-804, Feb. 2015.

[11] C.-C. Lin, L.-S. Yang, and G.-W. Wu, "Study of a non-isolated bidirectional DC-DC converter," IET Power Electron., vol. 6, no. 1, pp. 30-37, 2013

[12] P. J. Grbovi'c, P. Delarue, P. Le Moigne, and P. Bartholomeus, "A bidirectional three-level dc-dc converter for the ultracapacitor applications," IEEE Trans. Ind. Electron., vol. 57, no. 10, pp. 3415-3430, Oct. 2010.

[13] P. Wang, C. Zhao, Y. Zhang, J. Li, Y. Gao, "A bidirectional three-level DC-DC converter with a wide voltage conversion range for hybrid energy source electric vehicles," J. Power Electron., vol. 17, no. 2, pp. 334-345, Mar. 2017.

[14] K. Jin, M. Yang, X. Ruan, and M. Xu, "Three-level bidirectional converter for fuel-cell/battery hybrid power system," IEEE Trans. Ind. Electron., vol. 57, no. 6, pp. 1976-1986, Jun. 2010.

[15] P. Das, S. A. Mousavi, and G. Moschopoulos, "Analysis, design, and control of a nonisolated bidirectional ZVS-PWM dc-dc converter with coupled inductors," IEEE Trans. Power Electron., vol. 25, no. 10, pp. 2630-2641, Oct. 2010.

[16] P. Jose and N. Mohan, "A novel ZVS bidirectional cuk converter for dual voltage systems in automobiles," in Proc. IEEE IECON Conf. Rec., 2003, pp. 117-122.

[17] I.-D. Kim, S.-H. Paeng, J.-W. Ahn, E.-C. Nho, and J.-S. Ko, "New bidirectional ZVS PWM Sepic/Zeta DC-DC converter," in Proc. IEEE ISIE Conf. Rec., 2007, pp. 555-560.

[18] R. J. Wai and R. Y. Duan, "High-efficiency bidirectional converter for power sources with great voltage diversity," IEEE Trans. Power Electron., vol. 22, no. 5, pp. 1986-1996, Sep. 2007

[19] J. Yao, A. Abramovitz, and K. Smedley, "Steep gain bi-directional converter with a regenerative snubber," IEEE Trans. Power Electron., vol. 30 , no. 12 , pp. $6845-6856$, Dec. 2015

[20] M. Shah, J. Sutaria, and C. Chauhan, “ Design, simulation and implementation of two phase interleaved bi-directional DC-DC converter," in Proc. IEEE EESCO Conf. Rec., 2015, pp. 1-6.

[21] S. Busquets-Monge, S. Alepuz, and J. Bordonau, "A bidirectional multilevel boost-buck dc-dc converter," IEEE Trans. Power Electron., vol. 26, no. 8, pp. 2172-2183, Aug. 2011.

[22] H. S. H. Chung, W. C. Chow, and S. Y. R. Hui, "Development of a switched-capacitor dc-dc converter with bi-directional power flow," IEEE Trans. Circuits Syst., vol. 47, no. 9, pp. 1383-1390, Sep. 2000.

[23] H. S. Chung, A. Ioinovici, and W. L. Cheung, "Generalized structure of bi-directional switched-capacitor dc/dc converters," IEEE Trans. Circuits Syst. I, Fundam. Theory Appl., vol. 50, no. 6, pp. 743-753, Jun. 2003.

[24] K. Zou, M. J. Scott, and J. Wang, "A switched-capacitor voltage tripler with automatic interleaving capability," IEEE Trans. Power Electron., vol. 27, no. 6, pp. 2857-2868, Jun. 2012.

[25] O. Kirshenboim, and M. M. Peretz, "High-efficiency nonisolated converter with very high step-down conversion ratio," IEEE Trans. Power Electron., vol. 32, no. 5, pp. 3683-3690, May 2017.

[26] P. S. Shenoy, M. Amaro, J. Morroni, and D. Freeman, "Comparison of a buck converter and a series capacitor buck converter for high-frequency, high-conversion-ratio voltage regulators," IEEE Trans. Power Electron., vol. 31 , no. 10, pp. 7006-7015, Oct. 2016.

[27] H. Ardi, A. Ajami, F. Kardan, and S. N. Avilagh, "Analysis and implementation of a nonisolated bidirectional DC-DC converter with high voltage gain," IEEE Trans. Ind. Electron., vol. 63, no. 8, pp.
4878-4888, Aug. 2016.

[28] O. Cornea, G. D. Andreescu, N, Muntean, and H. Dan, "Bidirectional power flow control in a DC microgrid through a switched-capacitor cell hybrid DC-DC converter," IEEE Trans. Ind. Electron., vol. 64, no. 4, pp. 3012-3022, Apr. 2017.

[29] L. S. Yang and T. J. Liang, "Analysis and implementation of a novel bidirectional DC-DC converter,” IEEE Trans. Ind. Electron., vol. 59, no. 1, pp. 422-434, Jan. 2012.

[30] V. A. K. Prabhala, P. Fajri, V. S. P. Gouribhatla, B. P. Baddipadiga, and M. Ferdowsi, "A DC-DC converter with high voltage gain and two input boost stages," IEEE Trans. Power Electron., vol. 31, no. 6, pp. 4206-4215, Jun. 2016.

[31] B. Wu, K. Smedley, and S. Sigmond, "A new $3 X$ interleaved bidirectional switched capacitor converter," in Proc. IEEE Appl. Power Electron. Conf. Expo., 2014, pp. 1433-1439.

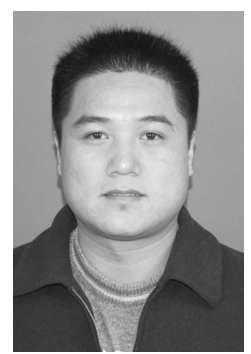

Yun Zhang (M'13) was born in Jiangsu, China, in 1980. He received the B.S. and M.S. degrees in electrical engineering from the Harbin University of Science and Technology, Harbin, China, in 2003 and 2006, respectively, and the Ph.D. degree in electrical engineering from the Harbin Institute of Technology, Harbin, China, in 2010

In 2010, he joined the Tianjin University, Tianjin, China, as a Lecturer in the School of Electrical and Information Engineering, where he is currently an Associate Professor. His current research interests include topologies, modulation, and control strategies of power converters for electric vehicles and microgrids. He is an Associate Editor of the Journal of Power Electronics.

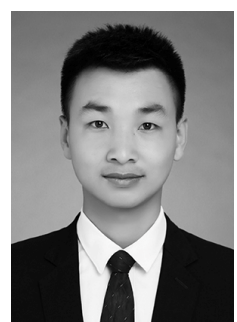

Yongping Gao was born in Shanxi, China. He received his B.S. degree in Electrical Engineering from the China University of Mining and Technology, Xuzhou, Jiangsu, China, in 2015. He started pursing his M.S. degree in Electrical Engineering from the Tianjin University, Tianjin, China, in 2015. His current research interests include power electronics converters, and energy management.

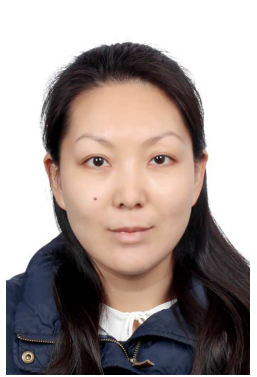

Jing Li (M'15) received the B.Eng. (Hons.) and M.Sc. (Distinction) degrees both in control science and engineering from the Beijing Institute of Technology, Beijing, China, in 1999, and 2002, respectively, and the Ph.D. degree in electrical engineering from the University of Nottingham, Nottingham, U.K., in 2010 .

She was a Research Fellow with the Power Electronic, Machine and Control Group, University of Nottingham. She is currently a Lecturer at the Department of Electrical and Electronic Engineering, University of Nottingham, Ningbo, China. Her research interests include condition monitoring for motor drive systems and power distribution systems and advanced control and design of motor drive systems.

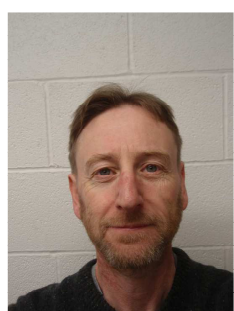

Mark Sumner (SM'05) received the B.Eng. degree in electrical and electronic engineering from Leeds University, Leeds, U.K., in 1986, and the Ph.D. degree in induction motor drives from the University of Nottingham, Nottingham, U.K., in 1992.

He was with Rolls Royce, Ltd., Ansty, U.K. He was a Research Assistant with the University of Nottingham, where he became a Lecturer in October 1992, and is currently a Professor of electrical energy systems. His research interests include control of power electronic systems including sensorlessmotor drives, diagnostics and prognostics for drive systems, power electronics for enhanced power quality, and novel power system fault location strategies. 